\title{
Study on Reasonable Roadway Position of Working Face under Strip Coal Pillar in Rock Burst Mine
}

\author{
Hengze Yang $\left(\mathbb{D}\right.$, Zhongping Guo $\mathbb{D}^{D}$, Daozhi Chen, Chao Wang, Fuyu Zhang, \\ and Zhaowen Du \\ College of Energy and Mining Engineering, Shandong University of Science and Technology, Qingdao 266590, Shandong, China \\ Correspondence should be addressed to Zhongping Guo; gzp57046@sdust.edu.cn
}

Received 18 August 2020; Revised 12 October 2020; Accepted 20 October 2020; Published 4 November 2020

Academic Editor: Qing Ma

Copyright (C) 2020 Hengze Yang et al. This is an open access article distributed under the Creative Commons Attribution License, which permits unrestricted use, distribution, and reproduction in any medium, provided the original work is properly cited.

\begin{abstract}
It is of great significance to study the reasonable position of mining roadway under strip coal pillar for increasing the stability of mining roadway, reducing the waste of resources, and realizing the safety production of working face. Based on the research background of the working face under the strip coal pillar in Jinqiao Coal Mine of Jining, Shandong Province, through theoretical analysis, similar material simulation experiment, and numerical simulation experiment, the stress distribution law, plastic failure range, and rationality of coal pillar setting in different width sections are systematically studied. Finally, the tailentry of working face is determined at the position of $5 \mathrm{~m}$ from the bottom of strip coal pillar to 1308 goaf. During the mining period of 1310 working face, the peak value of side abutment pressure is at the position of $3 \sim 4 \mathrm{~m}$; beyond $25 \mathrm{~m}$ in front of the coal wall, the deformation of the surrounding rock on the tailentry surface is small. After entering the advanced support section, the deformation of the two sides is mainly longitudinal crack expansion and local shallow small flakes; however, the roof is complete and stable. Therefore, the selection of tailentry location and coal pillar width has played a good role. The research results of this study can provide some reference for similar mine with similar geological and production technical conditions.
\end{abstract}

\section{Introduction}

With the development of coal industry for many years, there are few high-quality energy resources left in the eastern part of China, and the mining of deep resources faces many problems such as "three high and one disturbance," complex geological environment, and deterioration of mining environment. Therefore, the safe and efficient mining of high-quality resources under pressure in shallow areas is an urgent problem $[1,2]$. Many methods have been widely used in controlling surface subsidence to protect the surface buildings, such as strip mining, grout backfilling, and roompillar methods [3-6]. Thick seam is often mined by slicing and strip mining. After the top slicing coal seam is mined, strip coal pillar will be left. According to the theory of rock pressure, the stress in strip coal pillar will be redistributed under the influence of geological force and engineering force, and the phenomenon of stress concentration, elastic deformation, and plastic damage will occur in the strip coal pillar $[7,8]$. After the relocation of surface villages, the impact of mining on surface buildings can be ignored. The first mining area of Jinqiao Coal Mine adopts the fully mechanized top coal caving mining method to mine the remaining lower layer coal and the top layer left coal pillar. When strip coal pillar is mined in fully mechanized top coal caving face, problems such as uneven roof subsidence and abnormal stress distribution of coal body will occur. These abnormal phenomena affect the selection of tailentry position and the setting of section coal pillar. If the roadway location and coal pillar dimension are unreasonable, it will not only cause the support difficulty of tailentry but also may occur roof accident, rock burst accident, and so on. Therefore, it is of great significance to study the reasonable tailentry position and section pillar width under the strip coal pillar for the safe and efficient mining of the working face $[9,10]$. 
The research on the layout of mining roadway under strip coal pillar is less; however, this situation is similar to the study of roadway layout in close distance coal seam, roadway layout under large coal pillar, and reasonable width of coal pillar. Scholars at home and abroad have conducted rich research studies on these three aspects. Hao et al. [11-18], by using a variety of research methods, studied the stress distribution in the floor rock and the lower coal body during the mining of the close coal seam. In addition, the migration characteristics of the overlying rock in the stope are also studied. The reasonable layout position of the mining roadway is analyzed from the stress change rate and stress concentration degree. In close distance coal seam mining, the lower mining roadway layout should avoid high stress area and serious surrounding rock fracture area; it also proves the feasibility of mining roadway layout under the left coal pillar of the upper layer. Suchowerska et al. [19-21] studied the vertical stress distribution law of the floor of longwall working face, obtained the low stress area, and put forward the reasonable layout position of the lower layer roadway. Zhang et al. [22-24] built the coal pillar mechanical model, combined with the actual project, used the relevant mechanical theory and Mathcad software to determine the law of floor stress propagation and coal pillar width, and studied the stress distribution law of floor rock at different depths. By means of theoretical analysis and numerical simulation, Kong et al. [25] analyzed and discussed the failure depth of floor and the stress distribution of residual coal pillar in the floor after mining of middle and upper coal seams in close distance coal seam. At the same time, they proposed the reason why the roadway is easy to be damaged under nonuniform load and carried out roadway support research in view of this situation. Hou and Ma [26] analyzed the influence of interface friction angle, coal seam thickness, lateral support resistance, stress concentration coefficient, mining depth, cohesion, and other factors on the width of limit equilibrium zone. Based on the stress balance theory of loose medium, combined with stress differential balance equation, the width of limit equilibrium zone was calculated. Wang et al. [27-32] studied the reasonable coal pillar width under the corresponding specific geological conditions by means of numerical simulation, similar material simulation experiment, and theoretical analysis and carried out industrial experiments and field measurements to prove the stability of the reserved coal pillar width. It provides a great reference for the design of section coal pillar under similar conditions. Scholars at home and abroad have done a lot of research on the reasonable position of roadway and the reasonable width of section coal pillar; however, with the further research, the research on the special situation of arranging working face under the strip coal pillar in Jinqiao Coal Mine is less. In this study, the reasonable position of the tailentry and the width of the section coal pillar are deeply studied to realize the working face under the strip coal pillar safe and efficient mining.

\section{Engineering Background}

Jinqiao Coal Mine is the first mining area after putting into production. After nearly 10 years of mining, the south wing has been basically mined. Because of the influence of ground buildings, the north wing is designed to adopt layered strip mining. After the relocation of the existing surface villages, the lower layered coal body and some strip coal pillars are ready to be mined. The planned 1310 working face is arranged in the northwest of the mine, with the ground elevation of over $+35.4 \sim+37.1 \mathrm{~m}$ and the working face elevation of over $-434.9 \sim-412.0 \mathrm{~m}$. The proposed layout area of 1310 working face (red dotted line range) is located at the lower part of 1310 upper working face, the east is 1308 working face, the west is 1312 upper working face, the north is No. 3 coal seam scouring thinning zone, 1312 upper goaf is $77 \mathrm{~m}$ away from 1310 upper goaf, and the distance between 1308 goaf and 1310 upper goaf is $35 \mathrm{~m}$. The location of Jinqiao Coal Mine and the planned mining area of 1310 working face are shown in Figure 1.

\section{Analysis on Reasonable Range of Tailentry Layout under Strip Coal Pillar}

3.1. Stress Distribution under Strip Coal Pillar. In order to solve the pressure distribution problem under the strip coal pillar, the inclination of the working face is defined as a section, and the coal and rock strata at the bottom of the strip coal pillar are regarded as semiinfinite bodies; it is treated as a plane strain problem of elasticity. We set the weight of overlying strata $q$ as vertical stress loading on the strip coal pillar and establish the mechanical model as shown in Figure 2. The stress value of a certain point $M$ in the coal body at the bottom of the coal pillar and the rock layer under the coal body is calculated [33].

In order to obtain the stress state of point $M$ under the strip coal pillar, the coordinates of $M$ point are $(y, x)$, as shown in Figure 2. Set the tiny length $\mathrm{d} \zeta$ on $O Y$ axis from the origin of the coordinate $\zeta$ and regard the force $\mathrm{d} p=p \mathrm{~d} \xi$ on it as the microconcentrated force $\mathrm{d} \xi$. The horizontal distance between $M$ point and the microconcentrated force $\mathrm{d} p$ is $y-\xi$, and the vertical distance is $x$. For this small concentrated force, formula (1) can be applied [34]:

$$
\left.\begin{array}{c}
\mathrm{d} \sigma_{x}=-\frac{2 q \mathrm{~d} \xi}{\pi} \frac{x^{3}}{\left[x^{2}+(y-\xi)^{2}\right]^{2}}, \\
\mathrm{~d} \sigma_{y}=-\frac{2 q \mathrm{~d} \xi}{\pi} \frac{x(y-\xi)^{2}}{\left[x^{2}+(y-\xi)^{2}\right]^{2}}, \\
\mathrm{~d} \tau_{x y}=-\frac{2 q \mathrm{~d} \xi}{\pi} \frac{x^{2}(y-\xi)}{\left[x^{2}+(y-\xi)^{2}\right]^{2}}
\end{array}\right\}
$$




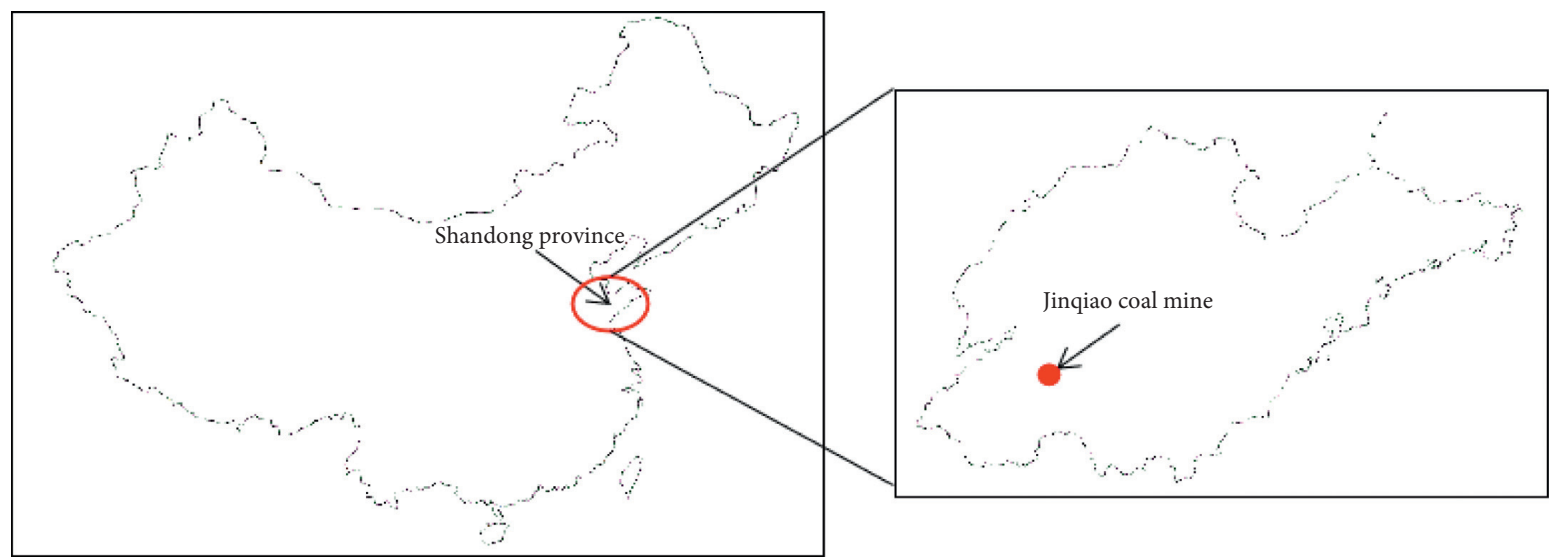

(a)

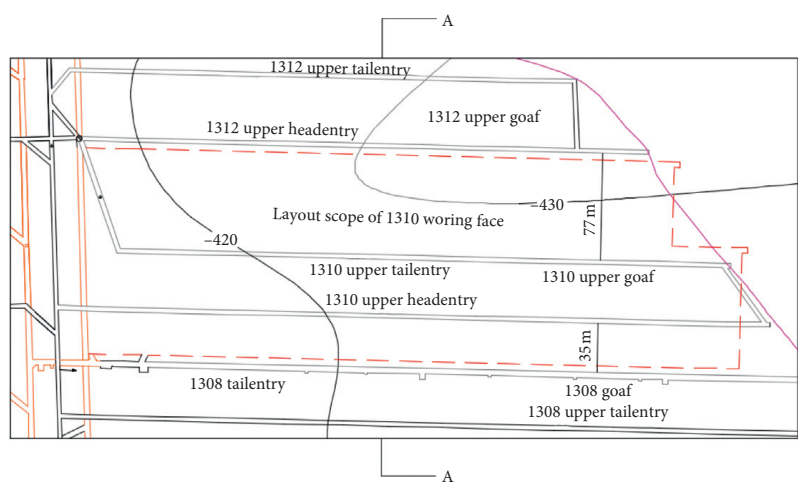

(b)

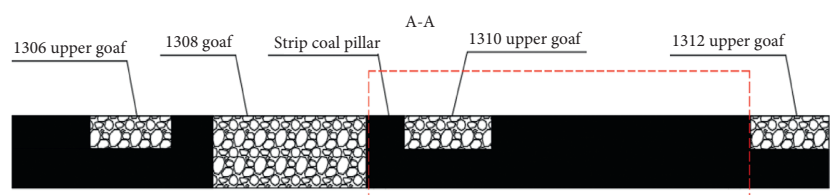

Layout scope of 1310 working face

FIGURE 1: Jinqiao coal mine location and layout scope of 1310 working face.

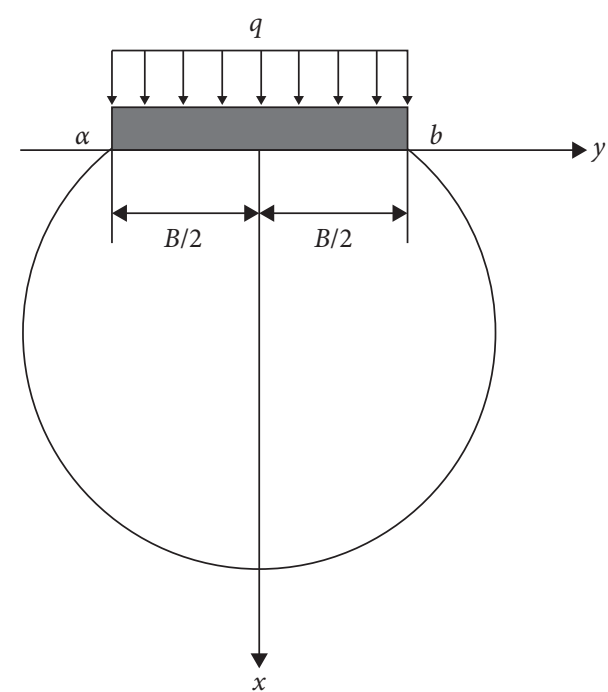

(a)

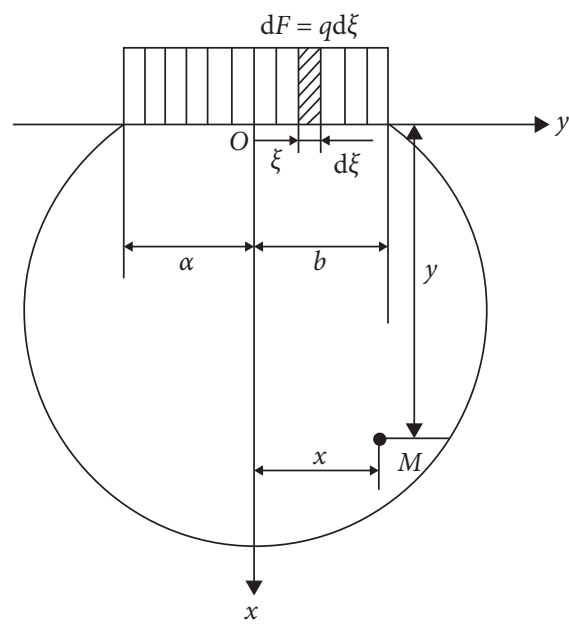

(b)

Figure 2: Mechanical model of strip coal pillar. 
For any segment of the boundary load, its integral is as formula:

$$
\left.\begin{array}{c}
\sigma_{x}=-\frac{2}{\pi} \int_{-b}^{a} \frac{q x^{3} \mathrm{~d} \xi}{\left[x^{2}+(y-\xi)^{2}\right]^{2}}, \\
\sigma_{y}=-\frac{2}{\pi} \int_{-b}^{a} \frac{q x(y-\xi)^{2} \mathrm{~d} \xi}{\left[x^{2}+(y-\xi)^{2}\right]^{2}}, \\
\tau_{x y}=-\frac{2}{\pi} \int_{-b}^{a} \frac{q x^{2}(y-\xi) \mathrm{d} \xi}{\left[x^{2}+(y-\xi)^{2}\right]^{2}} .
\end{array}\right\}
$$

By further integrating the stress state of point $M$, we can get formula:

$$
\begin{aligned}
& \sigma_{x}=\frac{q}{\pi}\left[\arctan \frac{y+b}{x}-\arctan \frac{y-a}{x}+\frac{x(y+b)}{x^{2}+(y+b)^{2}}-\frac{x(y-a)}{x^{2}+(y-a)^{2}}\right], \\
& \sigma_{y}=\frac{q}{\pi}\left[\arctan \frac{y+b}{x}-\arctan \frac{y-a}{x}-\frac{x(y+b)}{x^{2}+(y+b)^{2}}-\frac{x(y-a)}{x^{2}+(y-a)^{2}}\right], \\
& \tau_{x y}=\frac{q}{\pi}\left[\frac{x^{2}}{x^{2}+(y+b)^{2}}-\frac{x^{2}}{x^{2}+(y-a)^{2}}\right] .
\end{aligned}
$$

The strip coal pillar between 1308 goaf and 1310 upper goaf in Jinqiao Coal Mine is $35 \mathrm{~m}$, the uniform load $q$ is constant, and substituting formula (3), the variation diagram of vertical stress at different depths between the bottom of coal pillar left by the upper layer and strata in the lower layer is drawn by using MathCAD software, as shown in Figure 3.

It can be seen from Figure 3 that the stress concentration phenomenon appears at the bottom of the strip coal pillar from the inclination. The stress concentration area is bubble distribution, and the stress concentration degree of the bottom central part is the stress increasing area; taking the coal pillar center as the midpoint, the migration to the solid coal area on both sides is symmetrical distribution, and the area within $10 \mathrm{~m}$ from the edge of coal pillar on both sides is the low stress concentration area.

\subsection{Analysis of Failure Depth of Bottom Coal and Floor after} Mining in Upper Slicing Face. The model established by elastic-plastic theory is shown in Figure 4, and the failure depth $h_{1}$ of bottom coal and floor after mining in 1310 upper working face is calculated as follows [35]:

$$
h_{1}=\frac{1.57 \gamma^{2} H^{2} L}{4 \beta^{2} R_{c}^{2}} \text {, }
$$

where $\gamma$ refers to the average bulk density of overburden and is $25 \mathrm{kN} / \mathrm{m}^{3} ; H$ refers to the buried depth of the coal seam and is $460 \mathrm{~m}$; $L$ refers to the inclined length of working face 1310 and is $50 \mathrm{~m} ; \beta$ refers to the influence coefficient of joints and fissures and is 0.3 , and $R_{c}$ refers to the uniaxial compressive strength of coal seam and is $7.63 \mathrm{MPa}$.
The model established by slip line field theory and other relevant theoretical knowledge is shown in Figure 5, and the failure depth of bottom coal and floor is $h_{2}$ [35].

$$
\begin{aligned}
h_{2}= & \frac{M \cdot \cos \phi_{f} \cdot \ln \left(K \gamma H+c_{0} \cdot \cot \phi_{0} / \xi c_{0} \cdot \cot \phi_{0}\right)}{4 \xi \cdot f \cdot \cos \left((\pi / 4)+t\left(\phi_{f} / 2\right)\right)} \\
& \cdot e^{\left((\pi / 4)+\left(\phi_{f} / 2\right)\right) \tan \phi_{f}},
\end{aligned}
$$

where $M$ refers to the mining height of working face and is $2.2 \mathrm{~m} ; \phi_{f}$ refers to the internal friction angle of floor rock and is $28^{\circ}$; $K$ refers to the stress concentration factor of working face and is $2.5 ; c_{0}$ refers to the coal seam cohesion and is $1.25 ; \phi_{0}$ refers to the internal friction angle of coal seam and is $35^{\circ}$; $\zeta$ refers to the triaxial stress coefficient, $\xi=\left(1+\sin \phi_{0}\right) /\left(1-\sin \phi_{0}\right)$; and $f$ refers to the friction coefficient between coal seam and roof and floor, $f=\tan \phi_{0}$.

Through consulting the geological survey data and relevant laboratory data of Jinqiao Coal Mine and adjacent mines, the relevant parameters of upper layered goaf on the right side of strip coal pillar in Jinqiao Coal Mine are substituted into formulas (4) and (5), and the damage depth $h_{1}$ is $5.0 \mathrm{~m}$ and $h_{2}$ is $11.9 \mathrm{~m}$. Comparing the calculation results of the formulas derived from the two theories, for the sake of safety, we take the larger value as the guiding basis in the actual production. Therefore, the failure depth of the bottom coal and floor after the goaf of 1310 working face on the right side of the left coal pillar is $11.9 \mathrm{~m}$. The bottom coal and floor within $11.9 \mathrm{~m}$ below the 1310 upper layer goaf are seriously damaged, and the loose and broken surrounding rock is not conducive to the anchor bolt. Therefore, in view 


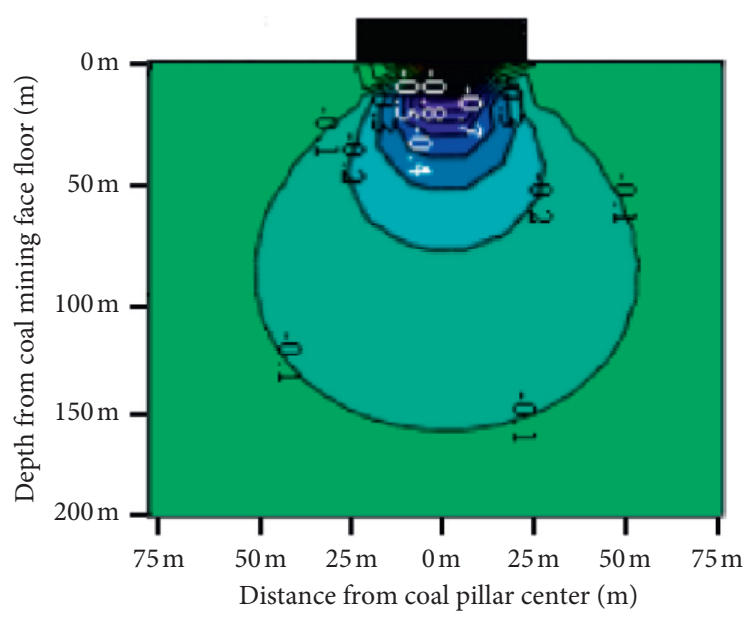

Figure 3: Vertical stress distribution at the bottom of strip coal pillar.

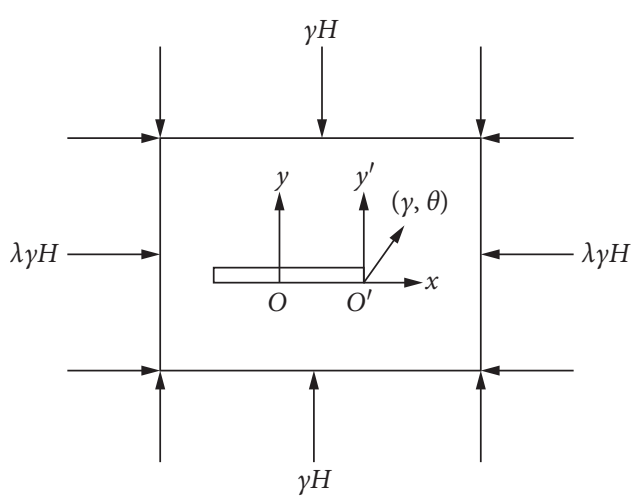

(a)

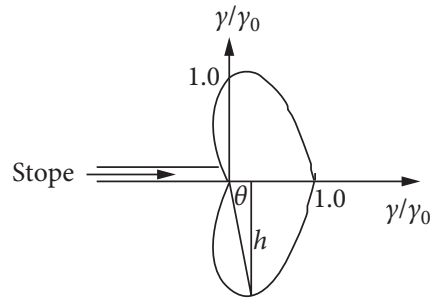

(b)

Figure 4: Stope mechanical model of plastic theoretical.

of resource saving and safe mining, the tailentry of 1310 working face should not be arranged in the lower part of 1310 upper goaf.

3.3. Analysis on Reasonable Width of Section Coal Pillar. The basic roof is composed of transfer rock beam. When its movement breaks, it will transfer the load generated by the upper strata of the basic roof to the surrounding coal and rock, and the abutment pressure on the coal and rock will be obviously divided into two parts, as shown in Figure 6. $S_{1}$ is the "internal stress field," and $S_{2}$ is the "external stress field."

According to the theory of internal and external stress field, small coal pillar should be selected to protect roadway when driving along goaf. Coal pillar should be arranged in "internal stress field." In this way, small coal pillar and mining roadway will be in a low stress environment, which is conducive to roadway support. Therefore, it is necessary to make clear the distribution range of "internal stress field" and the distribution of supporting pressure of "internal stress field" [36]. The formula is as follows:

$$
q=\int_{0}^{S_{1}} \sigma_{y} d x=\frac{G_{0} y_{0} S_{1}}{6}
$$

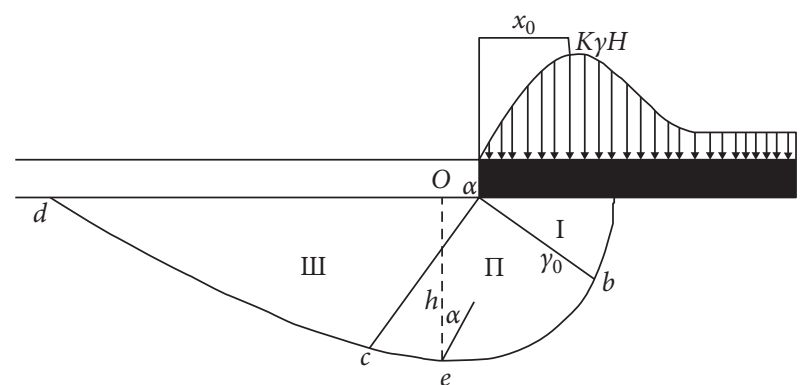

Figure 5: Theoretical mechanical model of slip line field.

where $\sigma_{y}$ is the side bearing pressure, $G_{0}$ is the coal stiffness, $y_{0}$ is the compression amount of coal body on coal wall, and $S_{1}$ is the distance from coal wall to goaf.

According to the relevant research, the peak value of abutment pressure in the range of internal stress field is equal to the self-weight of the basic roof when the working face is pressed for the first time. The following formula can be obtained [37]:

$$
\frac{G_{0} y_{0} S_{1}}{6}=\mathrm{LC}_{0} \sum_{i=1}^{n} M_{i} \gamma_{z}
$$




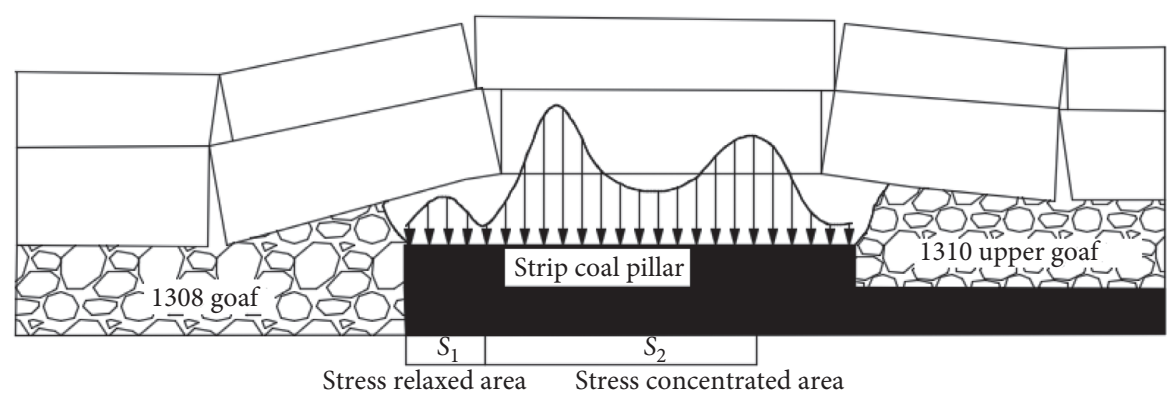

FIgURE 6: Distribution of abutment pressure on strip coal pillar.

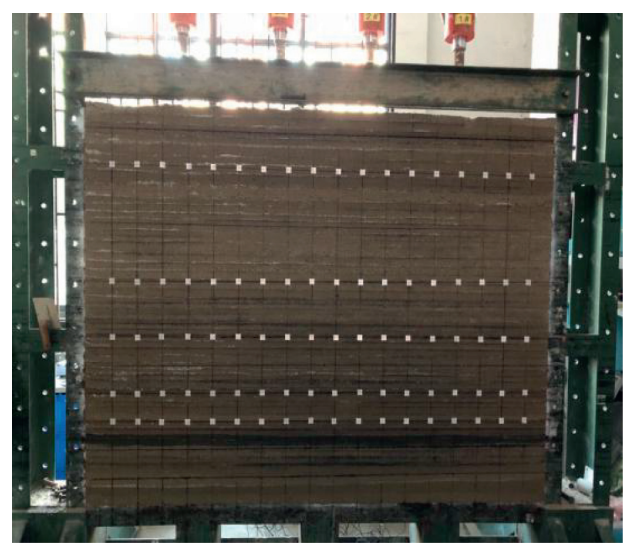

(a)

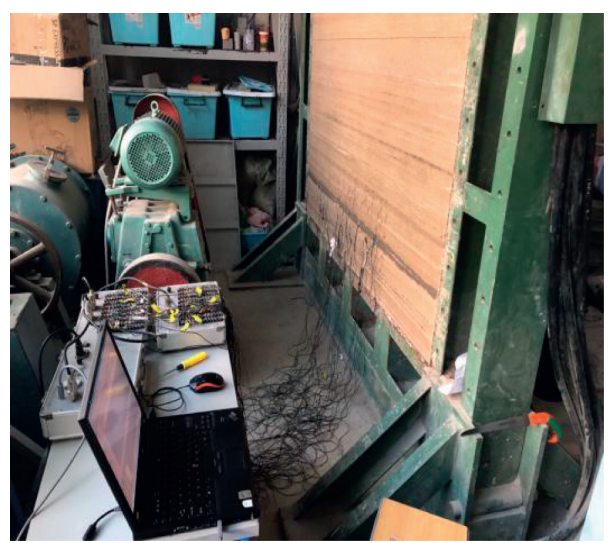

(b)

FIGURE 7: Laboratory equipment.

where $L$ is the inclined length of working face, $C_{0}$ is the first caving step distance of basic roof, $M_{i}$ is the basic top thickness, and $\gamma_{\mathrm{z}}$ is the average bulk density of basic roof.

Therefore, the internal stress field $S_{1}$ is as follows:

$$
S_{1}=\frac{1}{G_{0} y_{0}} 6 \mathrm{LC}_{0} \sum_{i=1}^{n} M_{i} \gamma_{z} .
$$

Through consulting the geological survey data and related experimental data of Jinqiao Coal Mine, we can know that the goaf length $L$ is $140 \mathrm{~m}$, the stiffness of coal body $G_{0}$ is $0.7 \mathrm{GPa}$, the coal compression at coal wall $y_{0}$ is $0.2 \mathrm{~m}$, the average bulk density of basic roof $\gamma$ is $2.5 \mathrm{kN} / \mathrm{m}^{3}$, the basic top thickness $M_{i}$ is $9.83 \mathrm{~m}$, and the first caving step of basic roof $C_{0}$ is $48 \mathrm{~m}$. Substituting the above parameters into formula (8), the internal stress field range $S_{1}$ is $7.07 \mathrm{~m}$.

\section{Similar Material Simulation Experiment on Overlying Rock Movement and Stress Distribution in Working Face 1310}

4.1. Experimental Conditions. The simulation test bench of similar materials in Key Laboratory (cultivation) of Shandong University of Science and Technology is selected as the experimental equipment. The dimension is $1.9 \times 0.22 \times 1.8 \mathrm{~m}$, and the laying height is $1.4 \mathrm{~m}$. The stress monitoring system adopts the DH3815N static strain testing system. The experimental equipment is shown in Figure 7.
4.2. Model Laying. The selected river sand (particle dimension between 0.1 and $0.35 \mathrm{~mm}$ ) is used as aggregate, gypsum and calcium carbonate are used as cementing materials, and mica powder is used for stratification between layers. Considering the material loss during the test, the material loss coefficient is taken as 1.1, the total amount of materials required for each layer is calculated according to formula (9), and the laying layers and ingredients are shown in Table 1. The model laying process is shown in Figure 8.

$$
W=v \times \gamma_{m}=l \times b \times h \times \gamma_{m} .
$$

4.3. Model Excavation and Monitoring Scheme. This model is a two-dimensional plane stress model. The excavation direction can be taken as the working face trend or the working face inclination direction. The excavation length of each working face in the design model is equal to the length converted according to the dimension similarity ratio of the working face inclination length in the actual project. Therefore, the overburden movement and stress distribution of the working face under the strip coal pillar can be studied from two perspectives. According to the actual site location and mining sequence, the excavation scheme of working face with similar material physical model is determined: 1308 upper working face $\longrightarrow 1310$ upper working face $\longrightarrow 1312$ upper working face $\longrightarrow 1308$ working face $\longrightarrow 1310$ working face. Coal pillars of different dimensions are reserved 
TABLE 1: Ratio of laying materials.

\begin{tabular}{|c|c|c|c|c|c|c|c|}
\hline \multirow{2}{*}{ No. } & \multirow{2}{*}{ Lithology } & \multirow{2}{*}{ Model thickness $(\mathrm{cm})$} & \multicolumn{4}{|c|}{ Material consumption $(\mathrm{kg})$} & \multirow{2}{*}{ Layer } \\
\hline & & & Sand & $\mathrm{CaCO}_{3}$ & Gypsum & Water & \\
\hline F20 & Mudstone & 6 & 54.84 & 2.06 & 4.80 & 8.81 & 2 \\
\hline F19 & Siltstone & 4 & 33.80 & 2.41 & 2.41 & 5.52 & 2 \\
\hline F18 & Sandy mudstone (S-M) & 2.5 & 21.83 & 0.82 & 1.91 & 3.51 & 1 \\
\hline F17 & Siltstone & 10 & 84.49 & 6.04 & 6.04 & 13.80 & 3 \\
\hline F16 & Fine sandstone (F-S) & 4.4 & 37.01 & 4.23 & 1.06 & 6.04 & 2 \\
\hline F15 & Mudstone & 4.6 & 42.05 & 1.58 & 3.68 & 6.76 & 2 \\
\hline F14 & Siltstone & 2.2 & 18.59 & 1.33 & 1.33 & 3.06 & 1 \\
\hline $\mathrm{F} 13$ & Mudstone & 13 & 118.82 & 4.45 & 10.40 & 19.10 & 6 \\
\hline F12 & S-M & 16 & 139.70 & 5.24 & 12.22 & 22.45 & 5 \\
\hline F11 & Mudstone & 11 & 100.54 & 3.77 & 8.80 & 16.16 & 5 \\
\hline F10 & S-M & 7.5 & 65.49 & 2.46 & 5.73 & 10.52 & 3 \\
\hline F9 & Siltstone & 5 & 42.24 & 3.02 & 3.02 & 6.90 & 2 \\
\hline F8 & Mudstone & 4.8 & 43.87 & 1.65 & 3.84 & 7.05 & 2 \\
\hline F7 & Siltstone & 7 & 59.14 & 4.22 & 4.22 & 9.66 & 4 \\
\hline F6 & Coarse sandstone (C-S) & 2.3 & 18.34 & 2.10 & 0.52 & 2.99 & 1 \\
\hline F5 & Medium sandstone & 4 & 32.33 & 3.23 & 1.39 & 5.28 & 1 \\
\hline F4 & F-S & 2.7 & 22.71 & 2.60 & 0.65 & 3.71 & 1 \\
\hline F3 & Siltstone & 2.4 & 20.29 & 1.44 & 1.44 & 3.31 & 1 \\
\hline $\mathrm{F} 2$ & F-S & 3 & 25.24 & 2.88 & 0.72 & 4.12 & 1 \\
\hline $\mathrm{F} 1$ & C-S & 2 & 15.95 & 1.82 & 0.45 & 2.60 & 1 \\
\hline $\mathrm{C}$ & $3^{\#}$ coal & 4 & 20.47 & 1.54 & 1.02 & 3.29 & 2 \\
\hline $\mathrm{R} 1$ & Siltstone & 4 & 33.80 & 2.41 & 2.41 & 5.52 & 2 \\
\hline $\mathrm{R} 2$ & F-S & 6 & 50.47 & 5.77 & 1.44 & 8.24 & 2 \\
\hline $\mathrm{R} 3$ & S-M & 4 & 34.93 & 1.31 & 3.06 & 5.60 & 2 \\
\hline $\mathrm{R} 4$ & C-S & 3.5 & 27.91 & 3.19 & 0.80 & 4.55 & 2 \\
\hline R5 & Mudstone & 4.3 & 39.31 & 1.47 & 3.44 & 6.32 & 2 \\
\hline
\end{tabular}

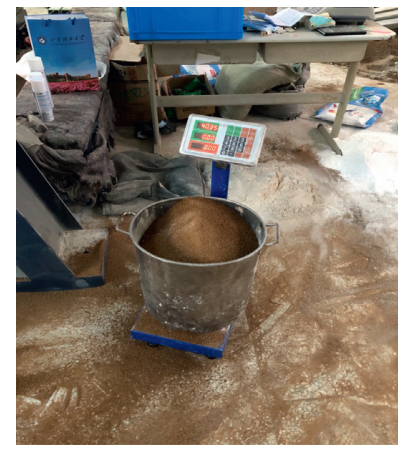

(a)

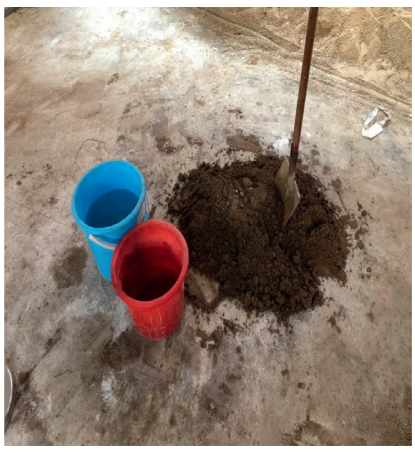

(b)

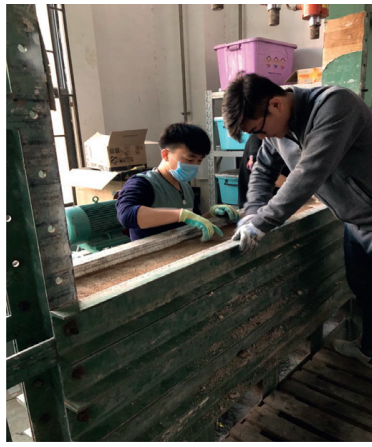

(c)

Figure 8: Model laying process.

between 1308 working face and 1310 working face. The reserved dimensions of coal pillars are designed as $15 \mathrm{~cm}$, $13 \mathrm{~cm}, 10 \mathrm{~cm}, 8 \mathrm{~cm}, 5 \mathrm{~cm}, 4.4 \mathrm{~cm}, 3.5 \mathrm{~cm}$, and $2 \mathrm{~cm}$, respectively, corresponding to the actual width of $35 \mathrm{~m}, 30 \mathrm{~m}$, $25 \mathrm{~m}, 18 \mathrm{~m}, 12 \mathrm{~m}, 10 \mathrm{~m}, 8 \mathrm{~m}$, and $5 \mathrm{~m}$. The excavation diagram is shown in Figure 9.

Stress monitoring method: total of 2 measuring lines are arranged in the physical model, with a total of 14 measuring points in line 1, with the spacing ranging from $5 \mathrm{~cm}$ to $10 \mathrm{~cm}$, which are arranged in the roof strata of the coal seam; total of 14 measuring points are arranged in the coal seam floor rock layer with the spacing of $5 \sim 10 \mathrm{~cm}$.
4.4. The Law of Overburden Failure When Coal Pillars with Different Widths Are Reserved. Six schemes with obvious experimental phenomena are selected from the 8 coal pillars setting schemes, and the movement law of overburden rock is shown in Figure 10. When the coal pillar with a width of $35 \mathrm{~m}$ is reserved, as shown in Figure 10(a), the coal pillar bears the load from the upper section 1308 overburden weight and the lower section 1310 working face transfer rock beam. The width of the section coal pillar is large, and the overall bearing capacity of the coal pillar is strong. In this case, the coal pillar is easy to accumulate elastic performance. The No.3 Coal Seam in Jinqiao Coal Mine has weak 


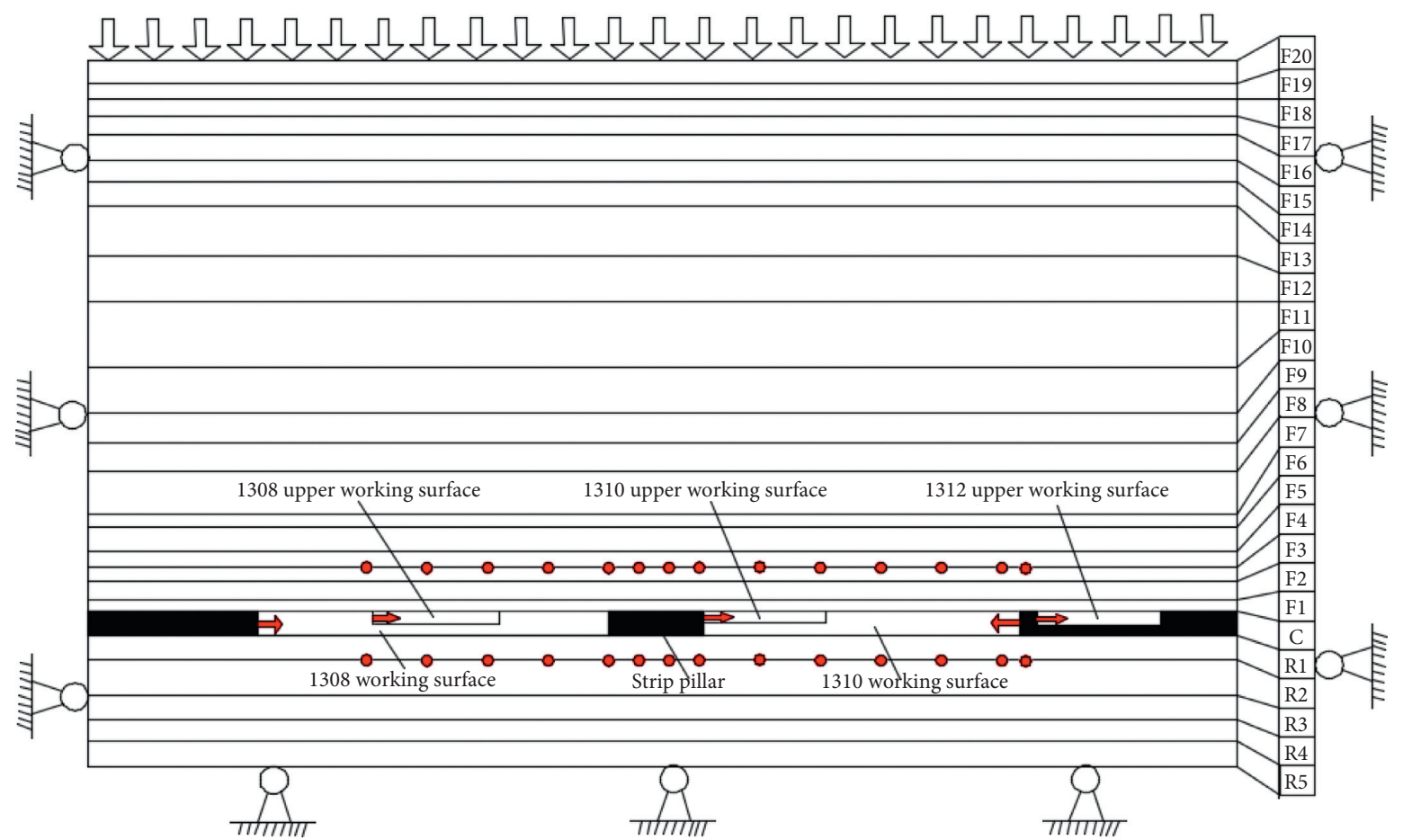

FIGURE 9: Model excavation and monitoring point layout.

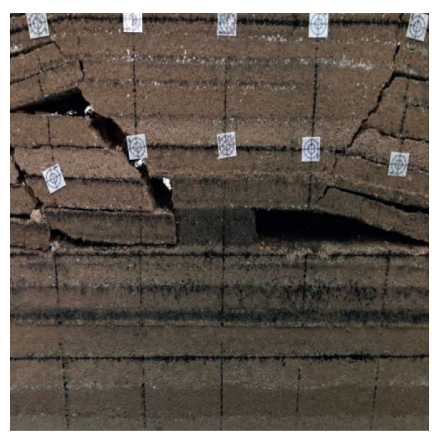

(a)

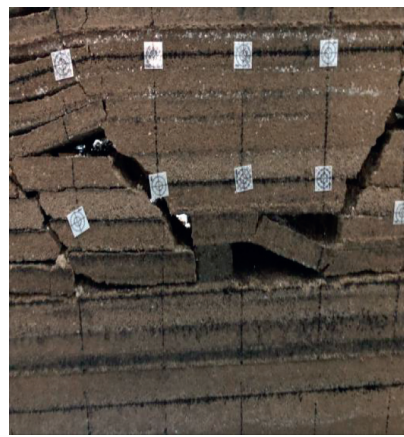

(d)

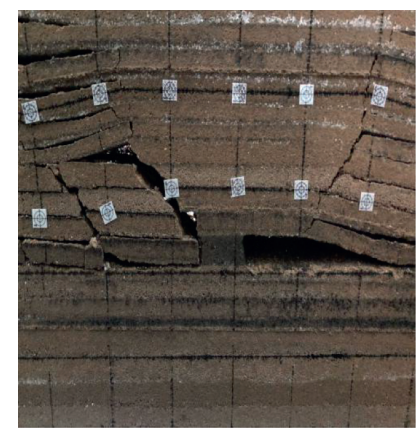

(b)

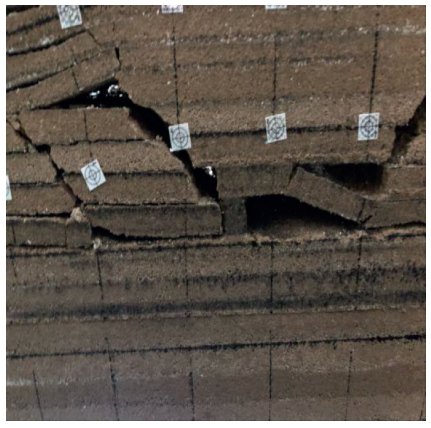

(e)

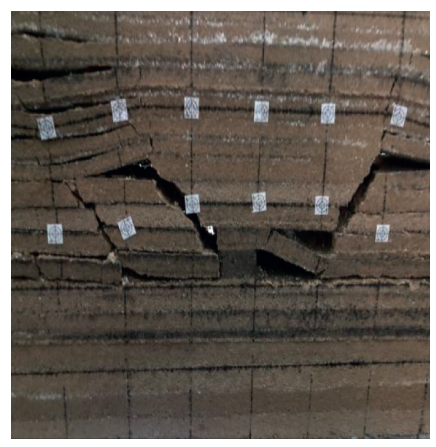

(c)

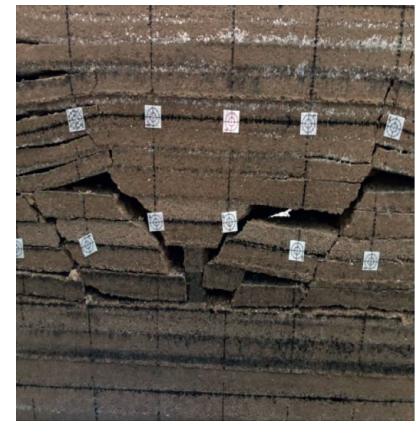

(f)

FIGURE 10: Movement law of overburden rock with different width coal pillars. (a) $35 \mathrm{~m}$ coal pillar. (b) $30 \mathrm{~m}$ coal pillar. (c) $25 \mathrm{~m}$ coal pillar. (d) $18 \mathrm{~m}$ coal pillar. (e) $10 \mathrm{~m}$ coal pillar. (f) $5 \mathrm{~m}$ coal pillar.

impact tendency. It is easy to trigger a large amount of energy to release suddenly under mining disturbance, which will lead to rock burst disaster. When the coal pillar with a width of $25 \mathrm{~m}$ is reserved, as shown in Figure 10(c), the hanging roof area increases, the roof weighting is strong, and the rock beam with the original hinged structure is fractured. 


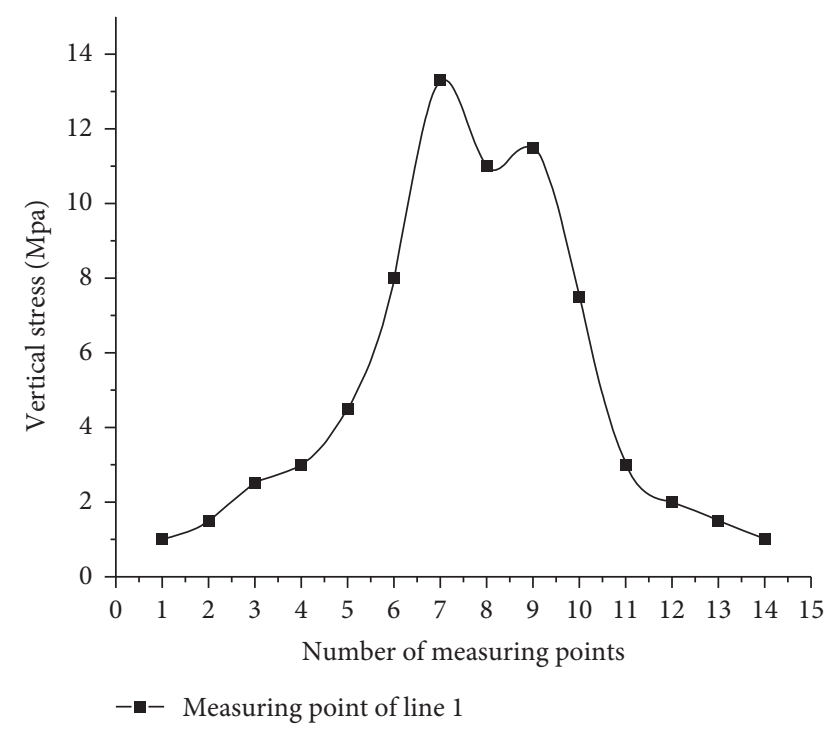

FIgURE 11: Pressure distribution curve of line 1.

At this time, cracks appear in the coal pillar, and the stress superposition of goafs on both sides of the coal pillar is serious, resulting in damage to the coal pillar. At this time, the pressure of the coal pillar is large and the integrity is reduced. As shown in Figure 10(e), when the coal pillar with a width of $10 \mathrm{~m}$ is reserved, the broken rock stratum in the goaf near the lower section of the coal pillar rotates, resulting in the pressure on the coal pillar increasing. As the width of the coal pillar decreases as far as possible, the basic roof hanging area increases. As shown in Figure 10(f), when the width of coal pillar is $5 \mathrm{~m}$, due to the pressure of hinged arch above it and the small width of coal pillar, the plastic failure of coal pillar occurs under large load, and the overlying rock above the coal pillar collapses at a faster speed. At this time, the goafs on both sides of the coal pillar are compacted, the floor pressure of goaf on both sides increases, the load of coal pillar bearing overburden decreases, and the coal pillar for roadway protection is neat. In the low stress environment, although the coal pillar edge has broken, however, the pillar can still maintain the supporting function.

4.5. Analysis of Stress Distribution Law. The layout of survey line 1 is shown in Figure 9. There are 14 stress sensors in total (serial numbers S1 S14 from left to right) and they are buried in the roof position of coal seam, which mainly monitors the change of roof pressure during the mining of each working face. According to the measured values of sensors in the experiment, after the mining of 1310 upper working face and 1308 working face, the distribution curve of roof pressure is shown in Figure 11.

It can be seen from Figure 11 that after the mining of 1310 upper working face and 1308 working face, the roof pressure in the two goafs is low, and the stress distribution

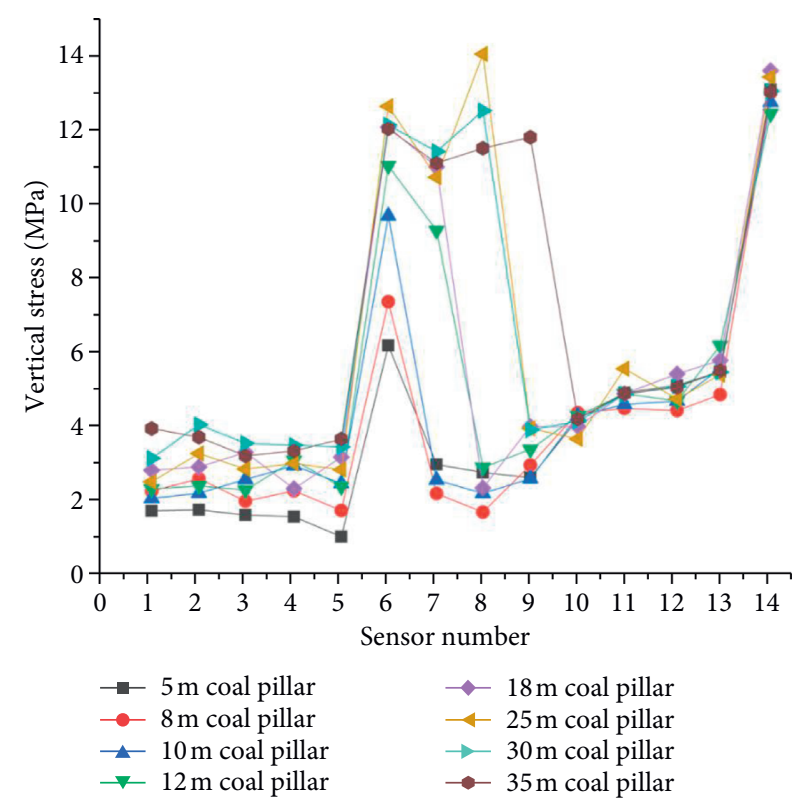

FIGURE 12: Floor pressure distribution curve.

on the left strip coal pillar presents "double hump" distribution, and the stress concentration degree of the side near the 1308 goaf is greater than that near the 1310 upper working face; the value of S5 sensor is less than the initial stress value, and the value of S6 sensor is higher than the initial stress value. The results show that the internal stress in $S 5 \sim S 6$ area is lower than that in the edge of 1308 goaf, and the stress value in the middle part of the left strip coal pillar is greater than that of the original rock, which indicates that the lateral abutment pressure of the two working faces produces stress superposition in the middle of the coal pillar after mining on both sides.

The layout of survey line 2 is shown in Figure 9. There are 14 stress sensors in total (number D1 D14 from left to right), and they are buried to monitor the changes of floor pressure during mining of each working face. According to the pressure value measured by sensors in the experiment, the floor pressure distribution curve of each working face after mining is shown in Figure 12.

It can be seen from Figure 12 that when the width of coal pillar is between 5 and $12 \mathrm{~m}$, the internal stress of coal pillar presents a single peak arrangement. When the coal pillar dimension is $5 \mathrm{~m}$, the overall bearing pressure in the coal pillar is the minimum, and the peak stress increases with the increase in coal pillar width; the peak value of internal stress in coal pillar increases with the increase in coal pillar width. When the coal pillar dimension is $25 \mathrm{~m}$, the peak value of coal pillar internal stress reaches the maximum among all coal pillar dimensions; when the coal pillar dimension is between $25 \mathrm{~m}$ and $35 \mathrm{~m}$, the peak stress value of coal pillar decreases with the increase in coal pillar width. 


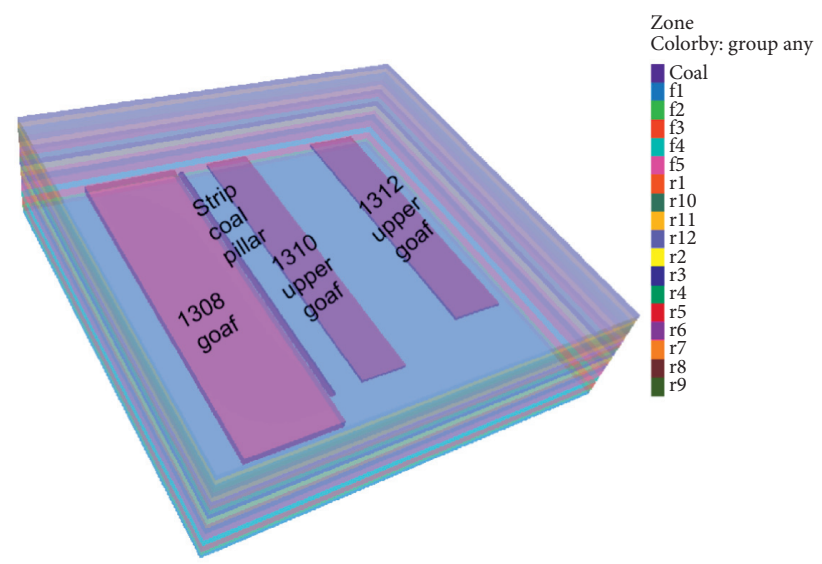

Figure 13: Numerical model.

TABLE 2: Mechanical parameters of coal and rock formations.

\begin{tabular}{|c|c|c|c|c|c|c|}
\hline No. & Lithology & Bulk modulus (GPa) & Shear modulus (GPa) & Tensile strength $(\mathrm{MPa})$ & Friction angle $\left({ }^{\circ}\right)$ & Cohesion (MPa) \\
\hline 1 & Sandy mudstone & 2.5 & 1.39 & 0.8 & 30 & 2.0 \\
\hline 2 & Siltstone & 9.66 & 11.48 & 1.2 & 33 & 3.4 \\
\hline 3 & Fine sandstone & 9.20 & 7.20 & 1.3 & 30 & 4.2 \\
\hline 4 & $3^{\#}$ coal & 1.8 & 2.75 & 0.7 & 25 & 2.0 \\
\hline 5 & Coarse sandstone & 9.23 & 8.10 & 1.1 & 26 & 5.5 \\
\hline 6 & Mudstone & 2.5 & 1.39 & 0.8 & 30 & 2.0 \\
\hline 7 & Medium sandstone & 10.22 & 11.52 & 1.6 & 35 & 2.6 \\
\hline
\end{tabular}

\section{Research on Reasonable Width of Coal Pillar in Lower Section of Strip Coal Pillar}

5.1. Establishment of Numerical Model. The coal pillar between 1308 goof and 1310 upper goof is selected as the test strip coal pillar, and the numerical calculation and analysis are carried out. $X$ axis is the inclined direction of the working face, $Y$ axis is the strike direction of the working face, and $Z$ axis is the vertical direction of the model. The dimension of the numerical model is as follows: length $\times$ width $\times$ height $=350 \times 550 \times 110 \mathrm{~m}$. The numerical model established is shown in Figure 13.

The boundary conditions of the model are as follows: the top is free boundary, the bottom boundary is fixed, the other faces are constrained by horizontal displacement, and the stress of $11.25 \mathrm{MPa}$ is applied to the upper boundary which is equivalent to $460 \mathrm{~m} \mathrm{mining} \mathrm{depth.} \mathrm{In} \mathrm{this} \mathrm{study,} \mathrm{the}$ Mohr-Coulomb model is used to simulate coal and rock mass. The mechanical parameters of coal and rock are shown in Table 2.

\subsection{Analysis on Reasonable Width of Section Coal Pillar during Roadway Driving in Working Face}

5.2.1. Stress Distribution Law of Surrounding Rock with Different Coal Pillar Width. In accordance with stress distribution law of surrounding rock with different coal pillar width, ensure that the coal pillar is arranged in the area with low abutment pressure, so as to reduce the deformation and damage of coal pillar, and ensure the internal integrity of coal pillar, which is helpful for the anchor rod to play its effective anchoring role, so as to ensure the stability of roadway during the service period. The preliminary design of six different section coal pillar dimensions under the strip coal pillar is carried out, and the section coal pillar retaining scheme is $4 \mathrm{~m}, 5 \mathrm{~m}, 8 \mathrm{~m}, 10 \mathrm{~m}, 13 \mathrm{~m}$, and $15 \mathrm{~m}$. The vertical stress distribution nephogram of coal pillar during roadway driving under strip coal pillar is shown in Figure 14.

Through the analysis of the above numerical simulation results, the vertical stress distribution characteristics of different dimension coal pillars can be obtained, and the stress distribution curves of coal pillars with different dimensions can be drawn according to the monitored vertical stress data, as shown in Figure 15.

According to the vertical stress distribution curve of coal pillar in different width sections, when the width of coal pillar is less than $5 \mathrm{~m}$, the overall vertical stress inside the coal pillar is smaller, and the peak stress is less than the initial stress; when the width of coal pillar is $5 \sim 8 \mathrm{~m}$, the surrounding rock pressure on both sides of tailentry is small; and when the width of coal pillar is between 8 and $15 \mathrm{~m}$, the peak value of abutment pressure appears in the side of near solid coal. Although the vertical stress in the coal pillar is greater than the initial stress, the stress concentration degree is not serious, and the stress concentration coefficient is 1.08 1.39; when the width of coal pillar is between $8 \mathrm{~m}$ and $15 \mathrm{~m}$, the peak value of abutment pressure appears in the section coal pillar, the overall abutment pressure in the coal pillar is larger, and the stress concentration factor is 

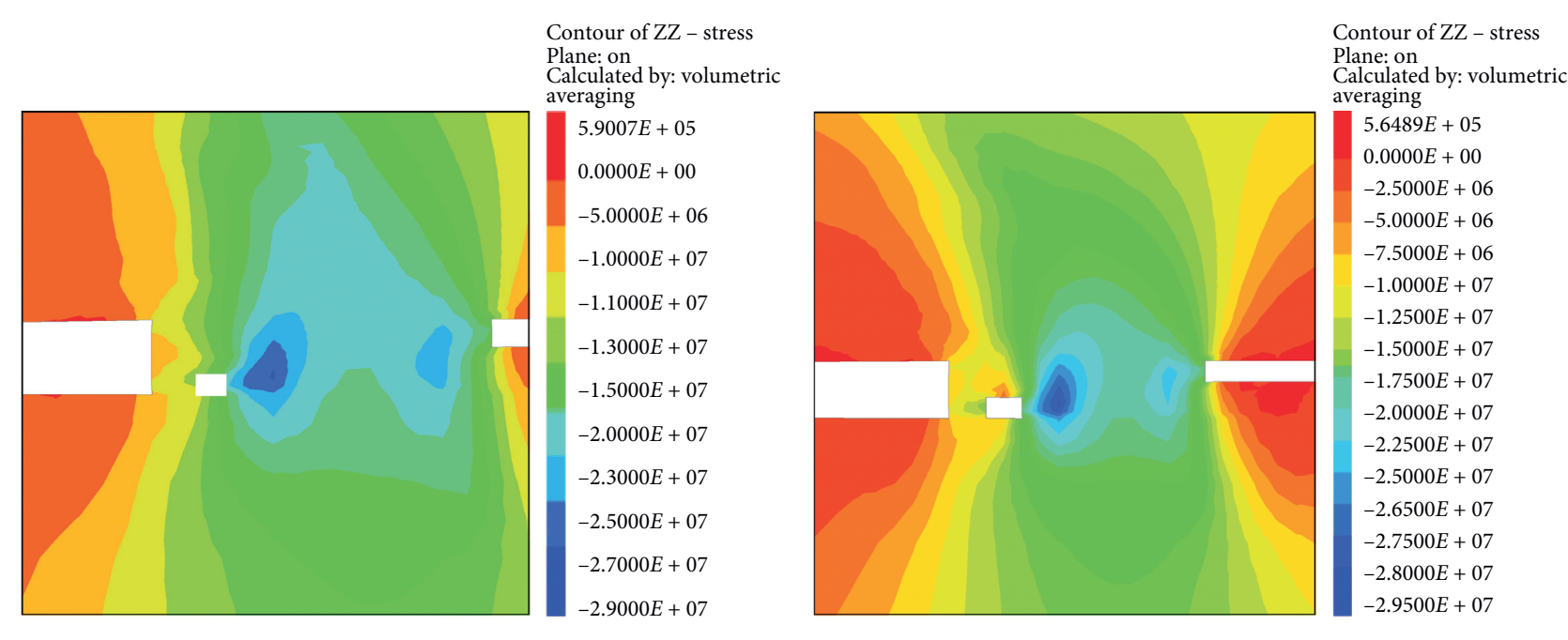

(a)

Contour of ZZ - stress Plane: on Calculated by: volumetric averaging

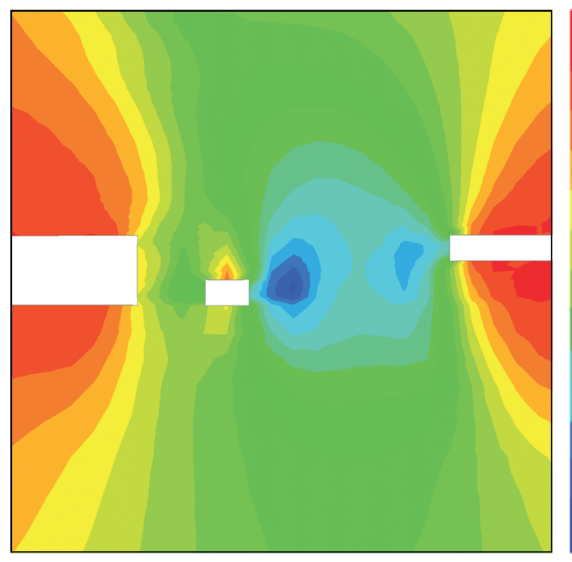
$5.3910 E+05$
$0.0000 E+00$
$-2.5000 E+06$
$-5.0000 E+06$
$-7.5000 E+06$
$-1.0000 E+07$
$-1.2500 E+07$
$-1.5000 E+07$
$-1.7500 E+07$
$-2.0000 E+07$
$-2.2500 E+07$
$-2.5000 E+07$
$-2.7500 E+07$
$-3.0500 E+07$

(c)

Contour of ZZ - stress

$$
\text { Plane: on }
$$

Calculated by: volumetric averaging

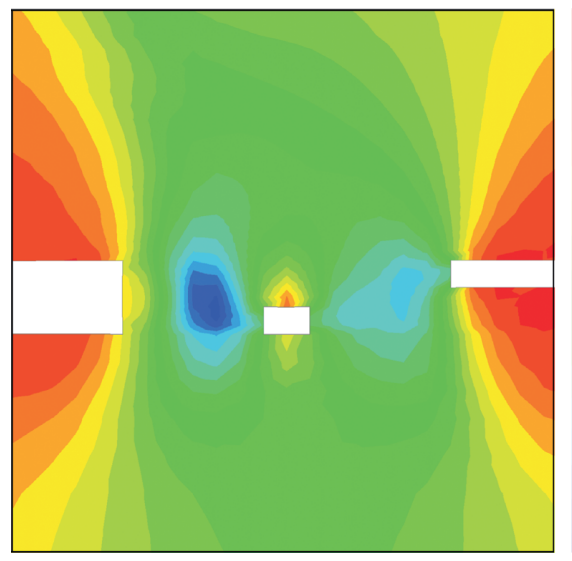

(e)
$5.4043 E+05$

$0.0000 E+00$

$-2.5000 E+06$

$-5.0000 E+06$

$-7.5000 E+06$

$-1.0000 E+07$

$-1.2500 E+07$

$-1.5000 E+07$

$-1.7500 E+07$

$-2.0000 E+07$

$-2.2500 E+07$

$-2.5000 E+07$

$-2.7500 E+07$

$-2.8500 E+07$

$-3.0000 E+07$

$-3.1500 E+07$ (b)

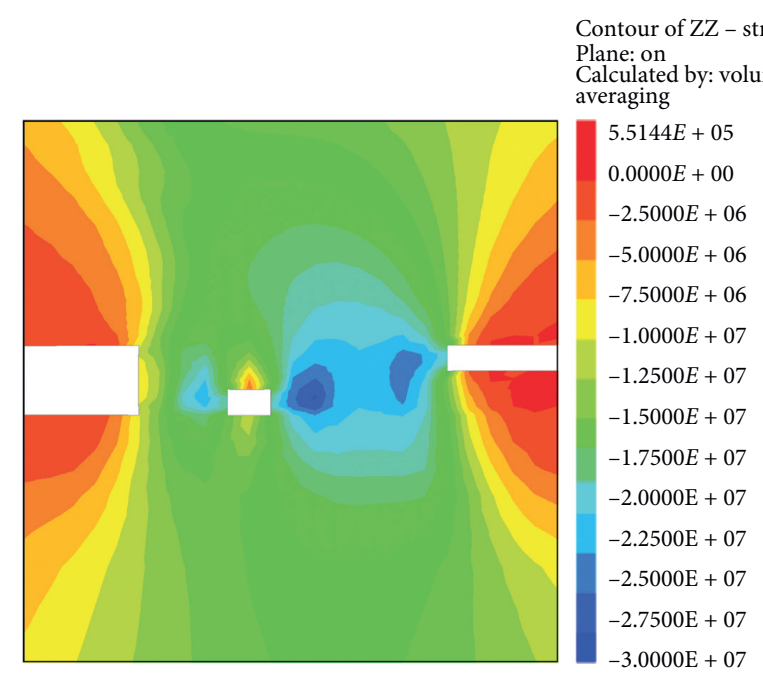

(d)

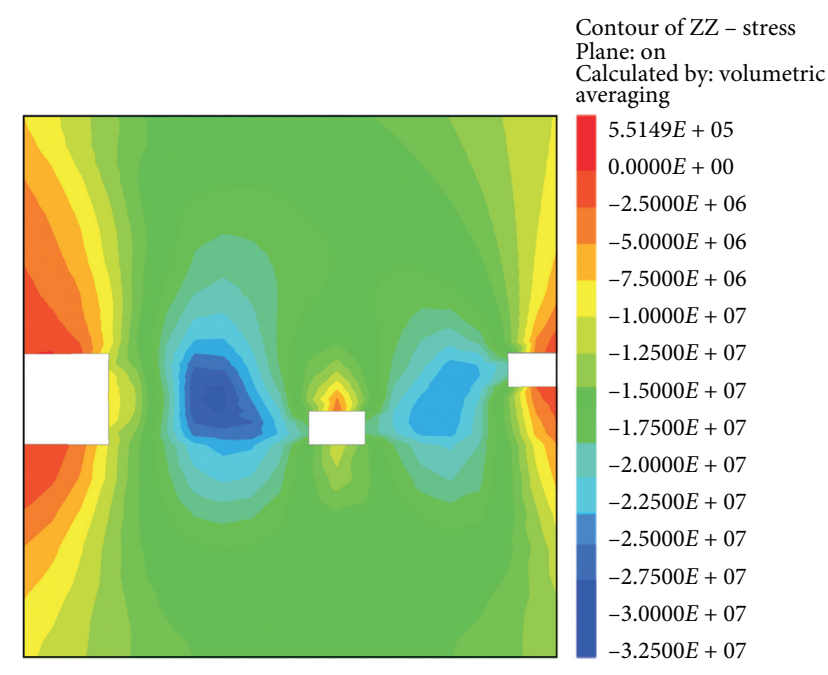

(f)

FIGURE 14: Vertical stress diagram of coal pillars in different width sections: (a) $4 \mathrm{~m}$, (b) $5 \mathrm{~m}$, (c) $8 \mathrm{~m}$, (d) $10 \mathrm{~m}$, (e) $13 \mathrm{~m}$, and (f) $15 \mathrm{~m}$. 


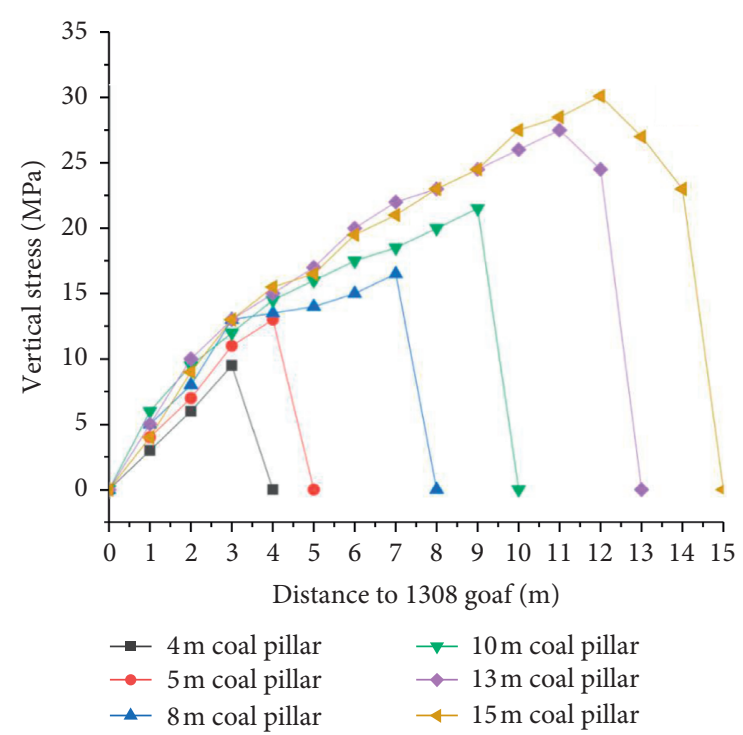

FIGURE 15: Vertical stress curves of coal pillars in different width sections.

$1.87 \sim 2.69$, the surrounding rock pressure on both sides of the tailentry is large, and it is easy to accumulate a lot of elastic energy. According to the stress distribution law in the coal pillar and both sides of the roadway, when the width of the coal pillar is greater than $8 \mathrm{~m}$, both sides of the tailentry bear high bearing pressure. With the increase in the width of the coal pillar, the stress concentration coefficient in the coal pillar is gradually increased, and the peak stress reaches $30.5 \mathrm{MPa}$, which is not conducive to the prevention and control of impact disasters and roadway support. Therefore, the coal pillar width is analyzed from the perspective of vertical stress distribution in coal pillar, the degree should be less than $8 \mathrm{~m}$, and it should be arranged between $4 \mathrm{~m}$ and $8 \mathrm{~m}$.

\subsubsection{Distribution of Plastic Zone in Different Coal Pillar} Width. The distribution of plastic failure zone of coal pillar with different dimensions can be obtained by profile along working inclined direction. The distribution of plastic failure zone of coal pillar in different dimension sections is shown in Figure 16. It can be seen from the analysis in Figure 16 that when the width of coal pillar is $4 \mathrm{~m}$, affected by the overlying rock movement after 1308 mining, the coal pillar undergoes shear failure, and the failure area covers the whole coal pillar. In addition, the rock around the roadway is seriously damaged and has internal deformation, and the shear failure is mainly accompanied by local tensile failure.

When the dimension of coal pillar is $5 \sim 8 \mathrm{~m}$, the plastic failure of the whole coal pillar occurs. The coal pillar relies on the residual strength after the peak to support the overburden, which weakens the damage around the roadway and reduces the deformation of the roadway. When the dimension of coal pillar is $8 \sim 15 \mathrm{~m}$, elastic element will be generated inside the coal pillar. With the increase in coal pillar width, the area of elastic area will increase, the plastic damage range of roof will be reduced, and the damage of tailentry will be significantly reduced.

Through the analysis of plastic failure of different coal pillar dimensions, it can be seen that when the section pillar dimension is $4 \mathrm{~m}$, the coal pillar is seriously damaged, and the supporting capacity of overburden rock is greatly reduced, resulting in serious roadway deformation and difficult support. Although the width of coal pillar is $8 \sim 15 \mathrm{~m}$, the supporting effect on the roof is similar to that of $5 \sim 8 \mathrm{~m}$ coal pillar. The increase in the elastic area is conducive to energy accumulation. However, it is not good for the prevention and control of the rock burst disaster. Therefore, it is suggested to set $5 \sim 8 \mathrm{~m}$ coal pillar from the perspective of the distribution of plastic failure area of coal pillar.

5.2.3. Displacement Nephogram of Coal Pillars with Different Widths. The horizontal displacement of coal pillars in different width sections can be obtained by profile along the inclined direction of working face. The horizontal displacement of coal pillars in different width sections can be seen in Figure 17.

The vertical displacement of coal pillars in different width sections can be obtained by profile along the working inclined direction. The vertical displacement of coal pillars in different width sections is shown in Figure 18, and the displacement curve of surrounding rock of coal pillars in different width sections is shown in Figure 19. Through the comprehensive analysis of Figures 17, 18, and 19, it can be seen that the roof subsidence is greater than the floor deformation, and the deformation of the coal pillar side is greater than that of the noncoal pillar side. The deformation of the roof and coal pillar side changes obviously with the width of the coal pillar; it increases first and then decreases with the increase in the width of the coal pillar, and the deformation of the noncoal pillar side and the floor with the width of the coal pillar is not clear, and the fluctuation range is small.

The results show that the deformation of roof is within $300 \mathrm{~mm}$, and the deformation of coal pillar side is within $250 \mathrm{~mm}$. With the increase in the coal pillar, the deformation of roof and coal pillar side is the largest, which is $280 \mathrm{~mm}$ and $230 \mathrm{~mm}$, respectively. The deformation is relatively large, the internal breakage of coal pillar is serious, and the stability is low, which is not conducive to the maintenance of roadway.

When the width of coal pillar is between 4 and $15 \mathrm{~m}$, the roof subsidence and the deformation of coal pillar side show a trend of decreasing first and then increasing, the deformation is the minimum at $5 \mathrm{~m}$, and the deformation gradually increases between 5 and $15 \mathrm{~m}$; the deformation of noncoal pillar side is within $150 \mathrm{~mm}$, and the deformation of floor is within $75 \mathrm{~mm}$, the change trend is gentle, and the deformation has been kept in a small range.

\section{Engineering Practice}

6.1. Field Application. According to the site geological conditions of Jinqiao Coal Mine in Jining, Shandong 

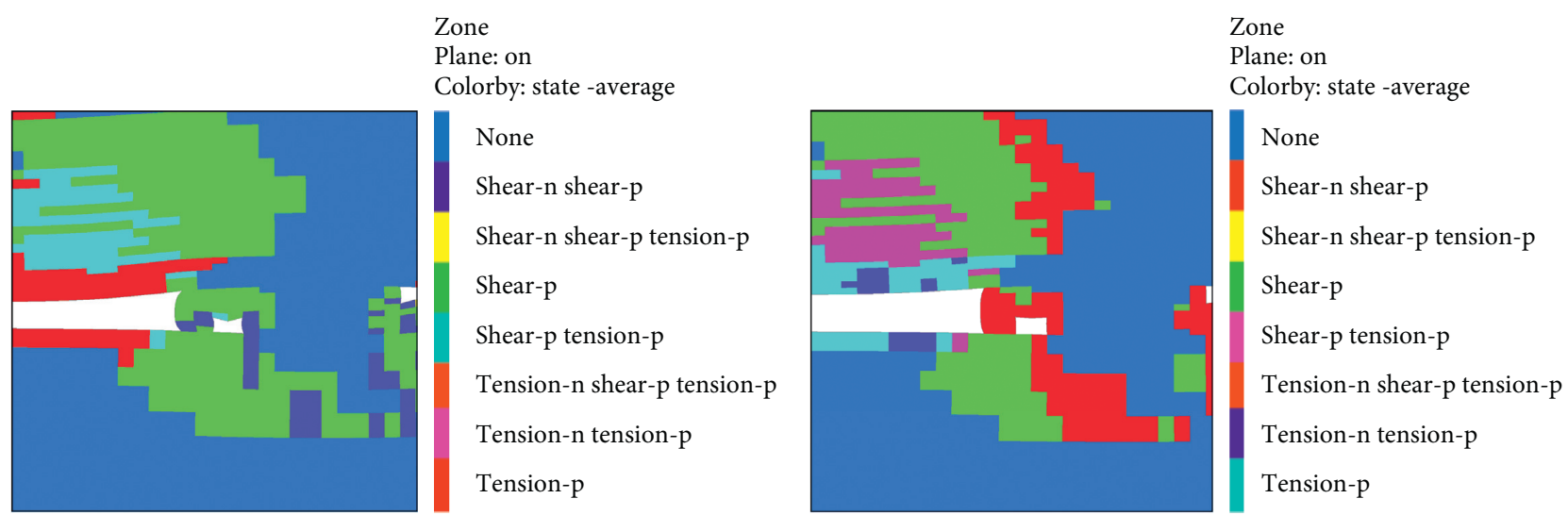

(a)

Zone

Plane: on

Colorby: state -average

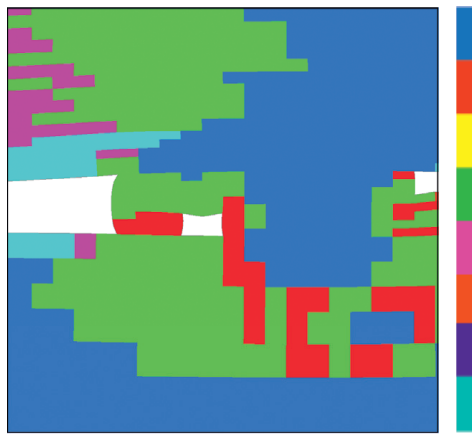

None

Shear-n shear-p

Shear-n shear-p tension-p

Shear-p

Shear-p tension-p

Tension- $n$ shear-p tension- $\mathrm{p}$

Tension-n tension- $p$

Tension-p

(b)

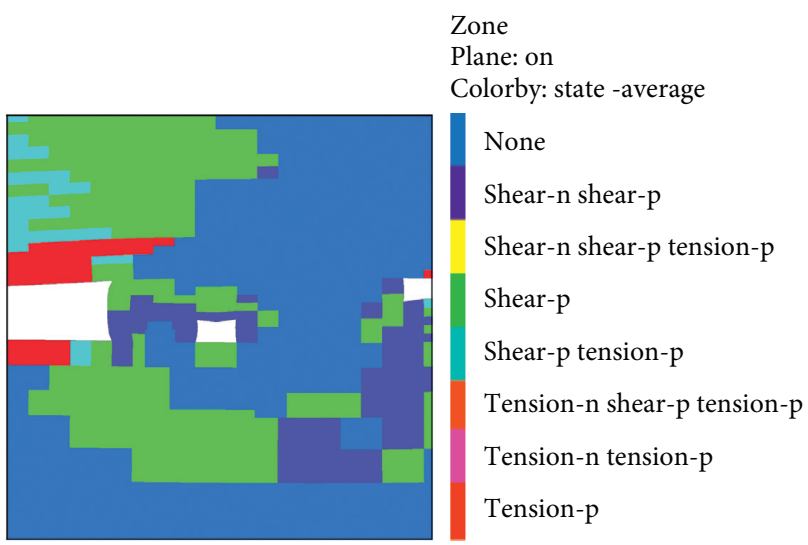

(c)

(d)

Zone

Plane: on

Colorby: state -average

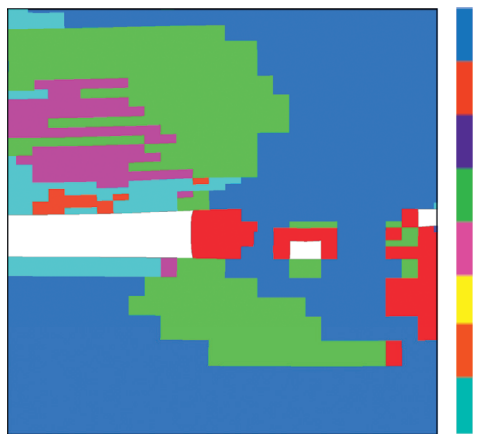

(e)
None

Shear-n shear-p

Shear-n shear-p tension- $p$

Shear-p

Shear-p tension- $p$

Tension-n shear-p tension- $p$

Tension-n tension-p

Tension-p
Zone

Plane: on

Colorby: state -average

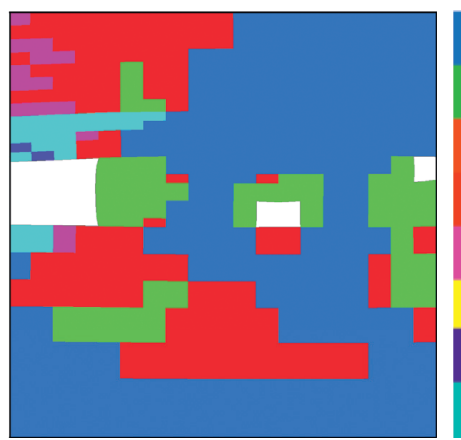

None

Shear-n shear-p

Shear-n shear-p tension-p

Shear-p

Shear-p tension-p

Tension-n shear-p tension-p

Tension-n tension-p

Tension-p

(f)

Figure 16: Distribution map of coal pillar plastic zone in different width sections: (a) $4 \mathrm{~m}$, (b) $5 \mathrm{~m}$, (c) $8 \mathrm{~m}$, (d) $10 \mathrm{~m}$, (e) $13 \mathrm{~m}$, and (f) $15 \mathrm{~m}$.

Province, and through the comprehensive analysis of the tailentry and coal pillar width of 1310 working face, it is determined that the tailentry is driven at the position of $5 \mathrm{~m}$ from the bottom of strip coal pillar to 1308 goaf, and the engineering practice is carried out in 1310 working face. The roadway layout of 1310 working face is shown in Figure 20.

6.2. Mine Pressure Observation Scheme. Taking the tailentry and $5 \mathrm{~m}$ small coal pillar in 1310 working face as the research object, the KJ513 wireless monitoring system of roof pressure and rock burst pressure, wireless digital pressure gauge, wireless borehole stress meter, laser rangefinder, gun, and other equipment were used to monitor the stability of tailentry and $5 \mathrm{~m}$ roadway protection pillar during service period and reveal the deformation law of tailentry and the stopping of 1310 working face. During this period, the evolution characteristics of ground pressure law are discussed.

According to the roadway layout of 1310 working face, two measuring areas are arranged for mine pressure observation, including 1 -advanced mining roadway measuring 


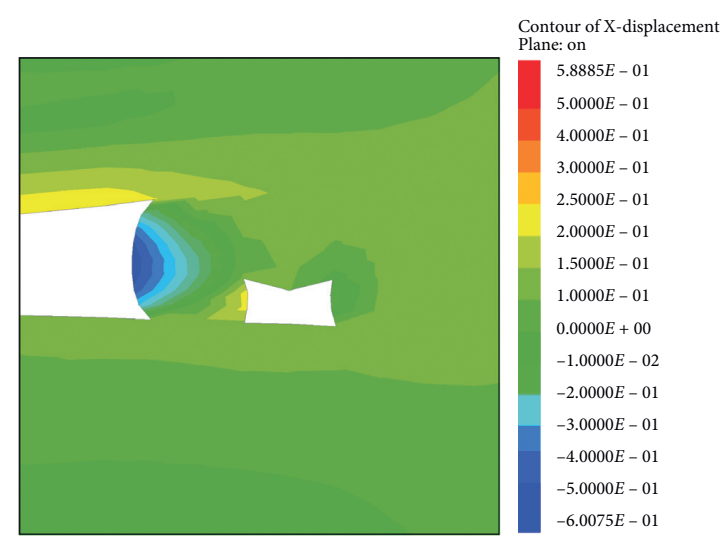

(a)

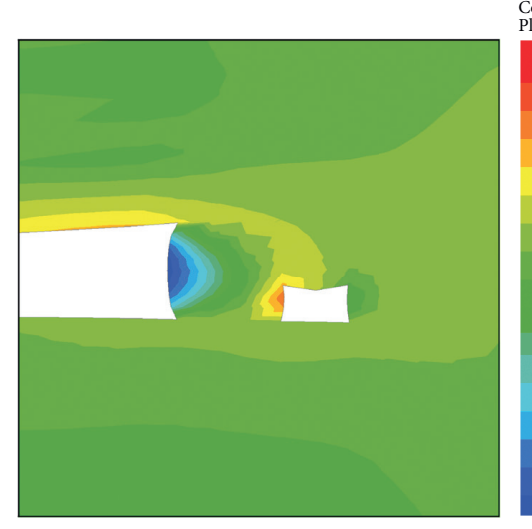

(c)

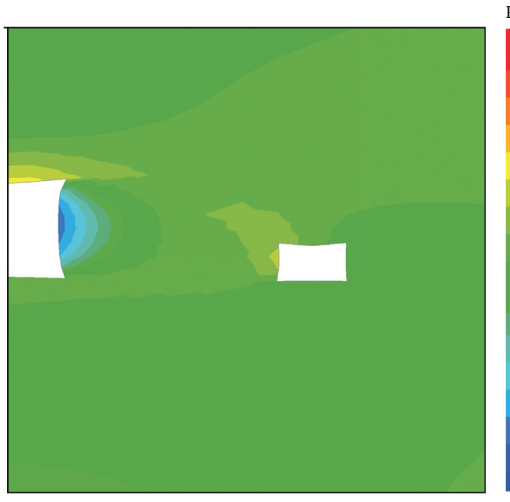

(e)

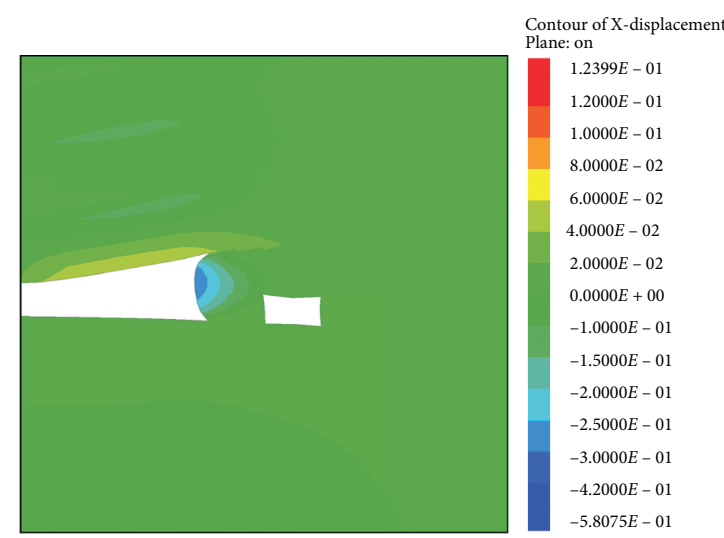

(b)

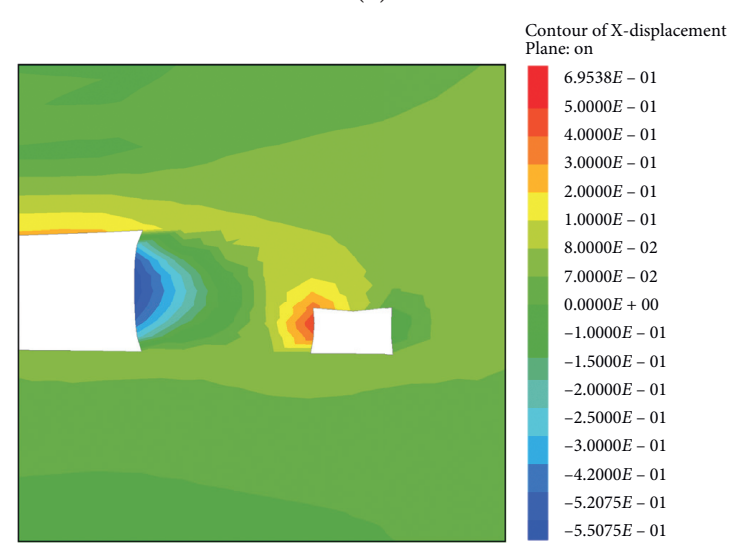

(d)

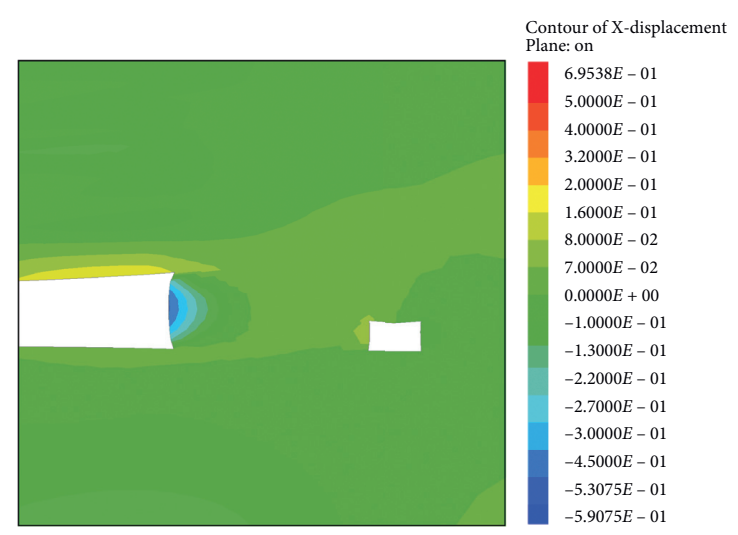

(f)

Figure 17: Horizontal displacement of coal pillar in different width section: (a) $4 \mathrm{~m}$, (b) $5 \mathrm{~m}$, (c) $8 \mathrm{~m}$, (d) $10 \mathrm{~m}$, (e) $13 \mathrm{~m}$, and (f) $15 \mathrm{~m}$.

area and 2-coal body measuring area. The layout of measuring areas is shown in Figure 21.

In the tailentry, the measuring stations are arranged at a distance of $10 \mathrm{~m}$ beyond the front coal wall. Each station contains two measuring lines. The measuring piles (A, B, C, and $D$ ) are arranged on both sides of the roadway and the roof and floor. The distance between the two piles is measured regularly with a measuring gun and a laser rangefinder. The measurement results are recorded, sorted out, and then analyzed. The layout of measuring points in the roadway is shown in Figure 22.
The coal stress measurement area is arranged at the stope and nonstope sides of 1310 belt conveyor roadway, which is used to observe and analyze the variation of advance abutment pressure and lateral abutment pressure with the advance of the working face. Starting from $90 \mathrm{~m}$ in front of the cut-off coal wall, there are 5 stopping side coal bodies that are constructed in the belt chute. As there are on-line monitoring points of rock burst stress nearby, the two points of " $8 \mathrm{~m}$ " and " $14 \mathrm{~m}$ " can be used. The installation depth is $3 \mathrm{~m}, 5 \mathrm{~m}, 7 \mathrm{~m}, 10 \mathrm{~m}$, and $12 \mathrm{~m}$, respectively, and the drilling spacing is $1 \mathrm{~m}$; There are 8 boreholes that are constructed in 


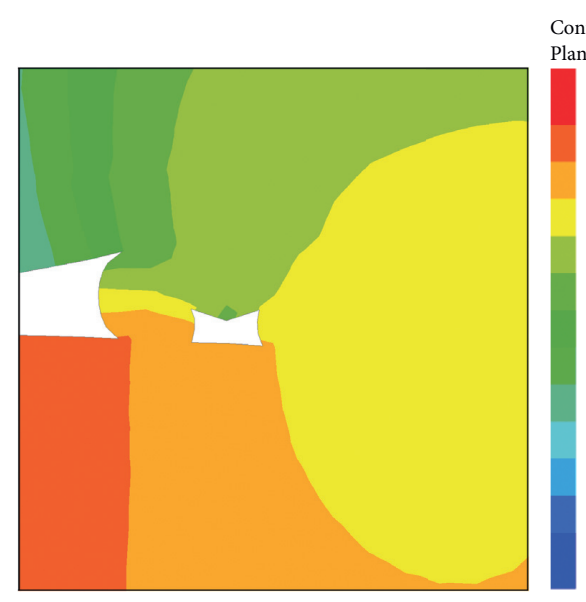

Plane: on

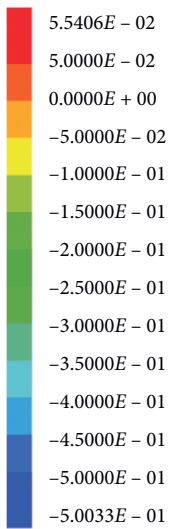

(a)

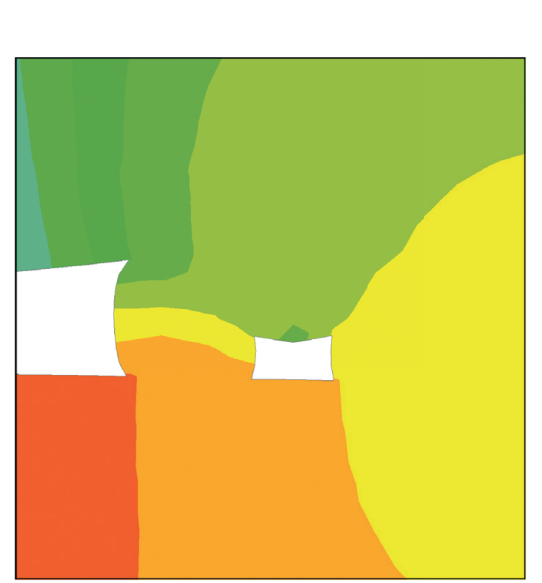

(c)

Contour of Z-displacement Plane: on

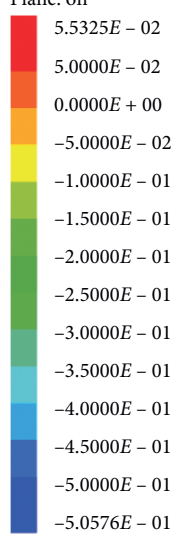

$-5.0576 E-01$

Contour of Z-displacement Plane: on

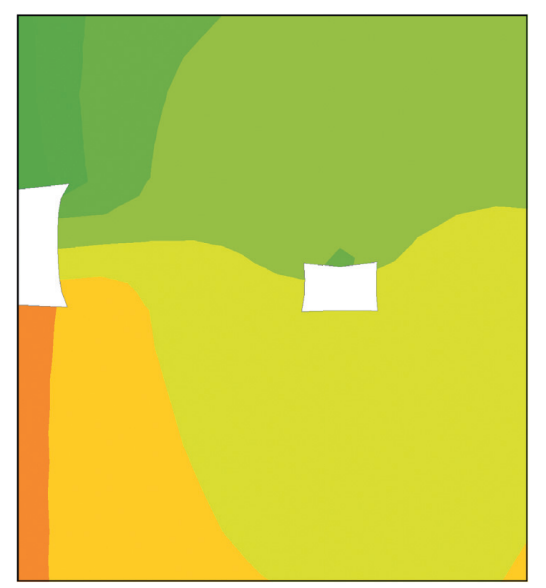

$5.5507 E-02$

$5.0000 E-02$

$2.5000 E-02$

$0.0000 E+00$

$-2.5000 E-02$

$-5.0000 E-02$

$-7.5000 E-02$

$-1.0000 E-01$

$-1.2500 E-01$

$-1.5000 E-01$

$-1.7500 E-01$

$-2.0000 E-01$

$-2.2500 E-01$

$-2.5000 E-01$

$-2.7500 E-01$

$-3.0000 E-01$

$-3.0038 E-01$

(e)
Contour of Z-displacement Plane: on

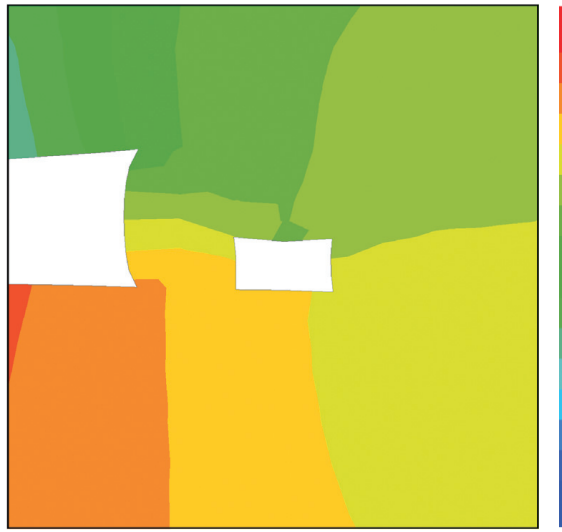

$5.5865 E-02$

$5.0000 E-02$

$2.5000 E-02$

$0.0000 E+00$

$-2.5000 E-02$

$-5.0000 E-02$

$-7.5000 E-02$

$-1.0000 E-01$

$-1.2500 E-01$

$-1.5000 E-01$

$-1.7500 E-01$

$-2.0000 E-01$

$-2.2500 E-01$

$-2.5000 E-01$

$-2.7500 E-01$

$-3.0000 E-01$

$-3.0337 E-01$

(b)

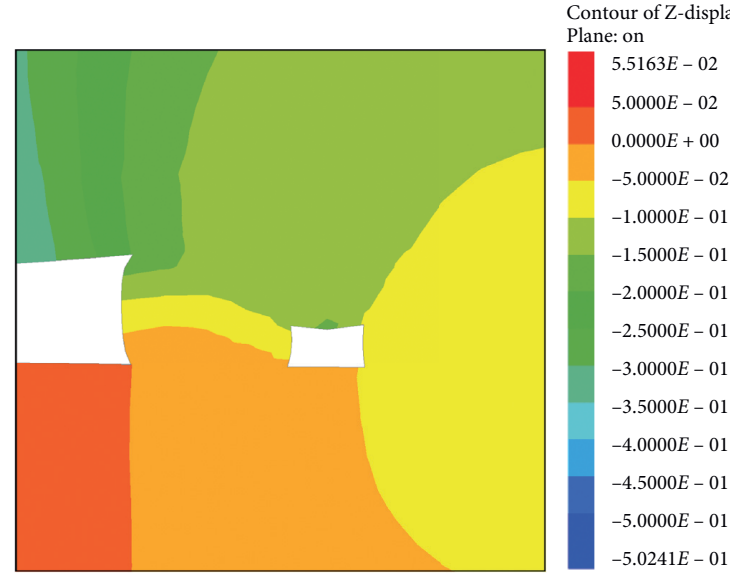

(d)

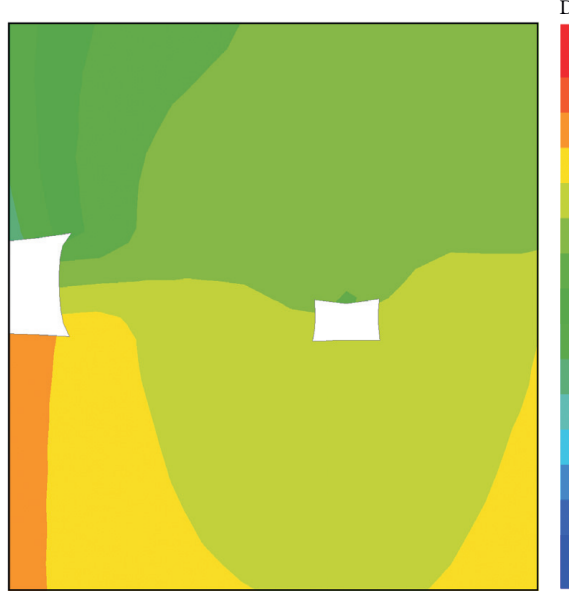

Contour of Z-displacement Plane: on Deformed factor: 10

$5.5502 E-02$

$5.0000 E-02$

$2.5000 E-02$

$0.0000 E+00$

$-2.5000 E-02$

$-5.0000 E-02$

$-7.5000 E-02$

$-1.0000 E-01$

$-1.2500 E-01$

$-1.5000 E-01$

$-1.7500 E-01$

$-2.0000 E-01$

$-2.2500 E-01$

$-2.5000 E-01$

$-2.7500 E-01$

$-2.9943 E-01$

(f)

FIgURE 18: Vertical displacement of coal pillar in different width sections: (a) $4 \mathrm{~m}$, (b) $5 \mathrm{~m}$, (c) $8 \mathrm{~m}$, (d) $10 \mathrm{~m}$, (e) $13 \mathrm{~m}$, and (f) $15 \mathrm{~m}$.

the nonmining side coal body, with the depth of $2 \mathrm{~m}, 4 \mathrm{~m}$, $5 \mathrm{~m}, 7 \mathrm{~m}, 9 \mathrm{~m}, 11 \mathrm{~m}$, and $13 \mathrm{~m}$, and the drilling spacing is $1 \mathrm{~m}$. One borehole stress gauge is installed in the hole, as shown in Figure 23.

\subsection{Analysis of Mine Pressure Law}

6.3.1. Deformation Law of Surrounding Rock in Advance Gateway. After the tailentry is affected by the advance 


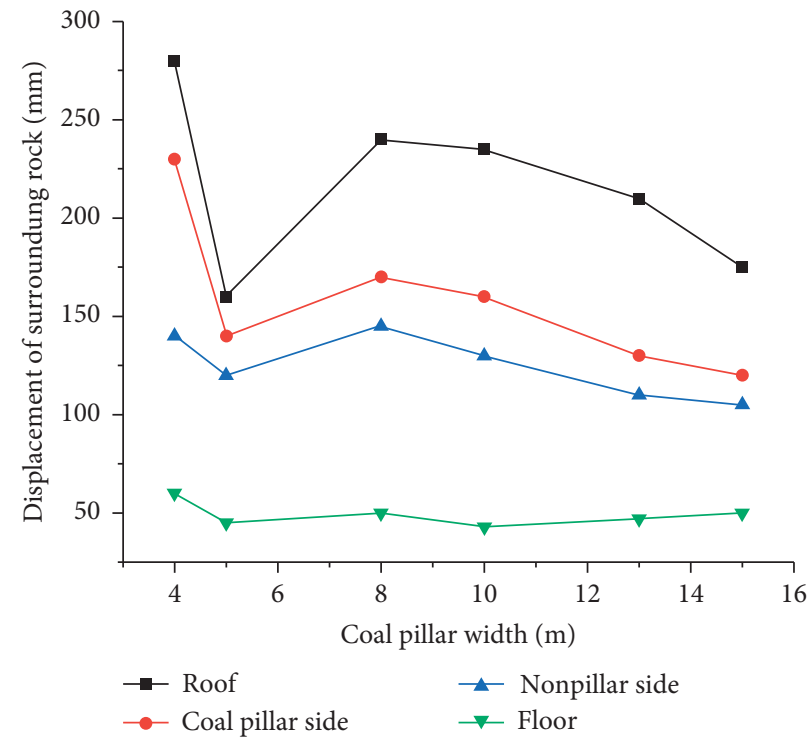

FIgURE 19: Displacement curves of coal pillars with different widths.

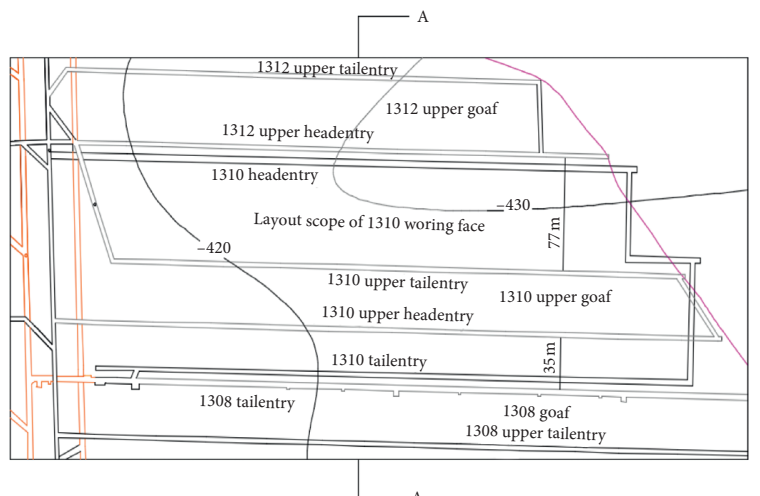

(a)

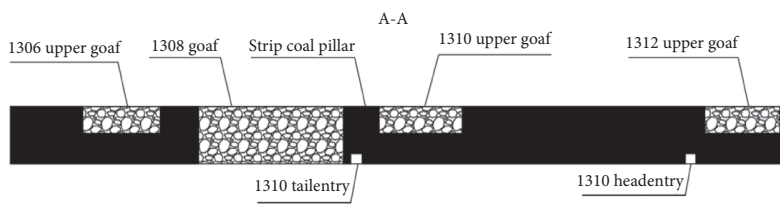

(b)

Figure 20: 1310 working face roadway layout plan.

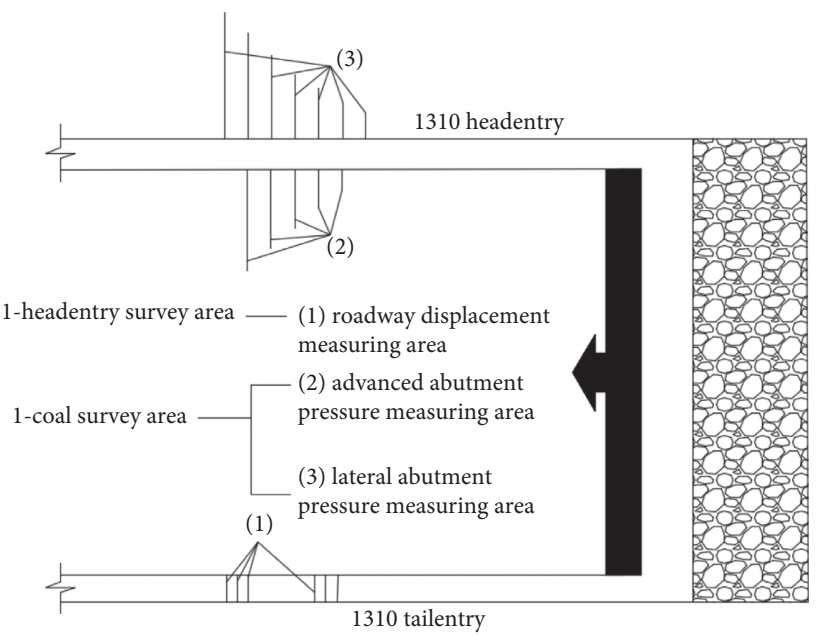

Figure 21: Layout of survey area.

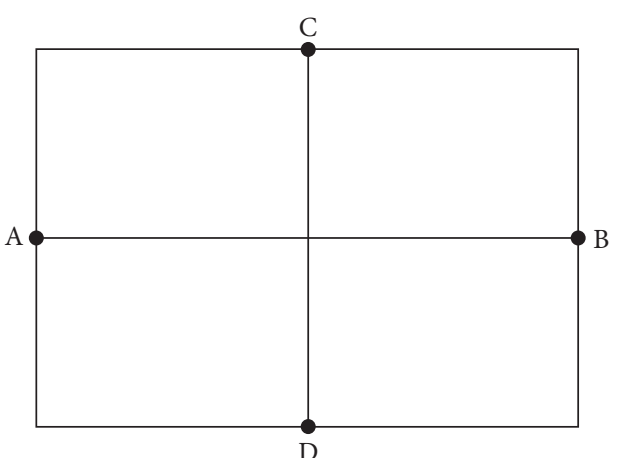

Figure 22: Layout of measuring points in roadway.

abutment pressure, the main manifestations are roof subsidence, floor bulging, and two sides moving close. This observation starts from the tailentry $100 \mathrm{~m}$ away from the 


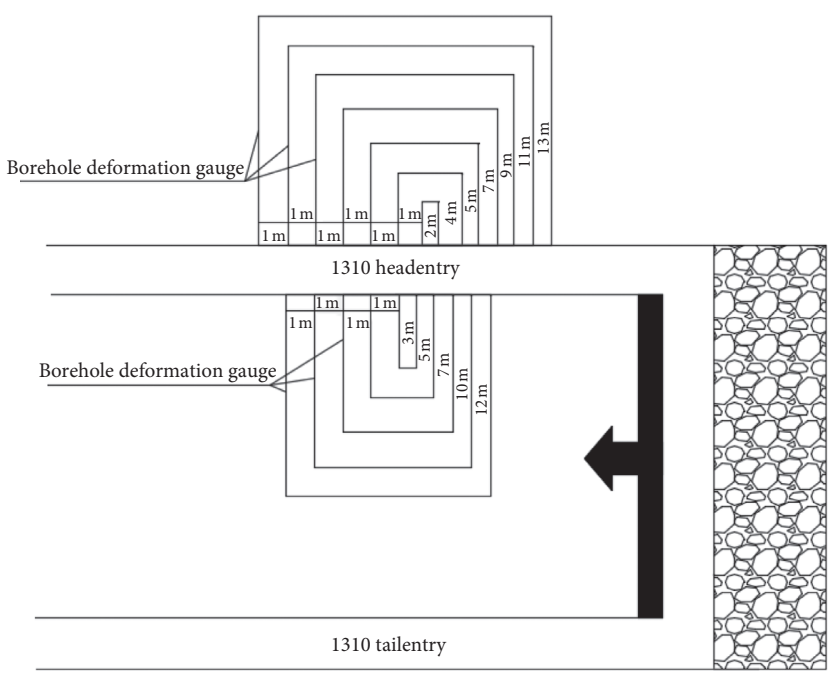

FIGURE 23: Layout of abutment pressure measuring points.

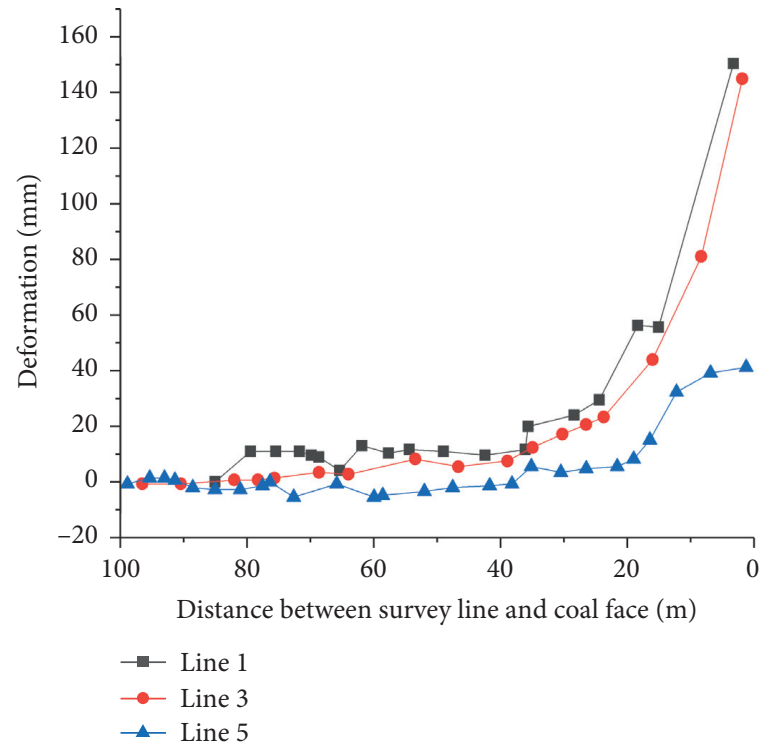

(a)

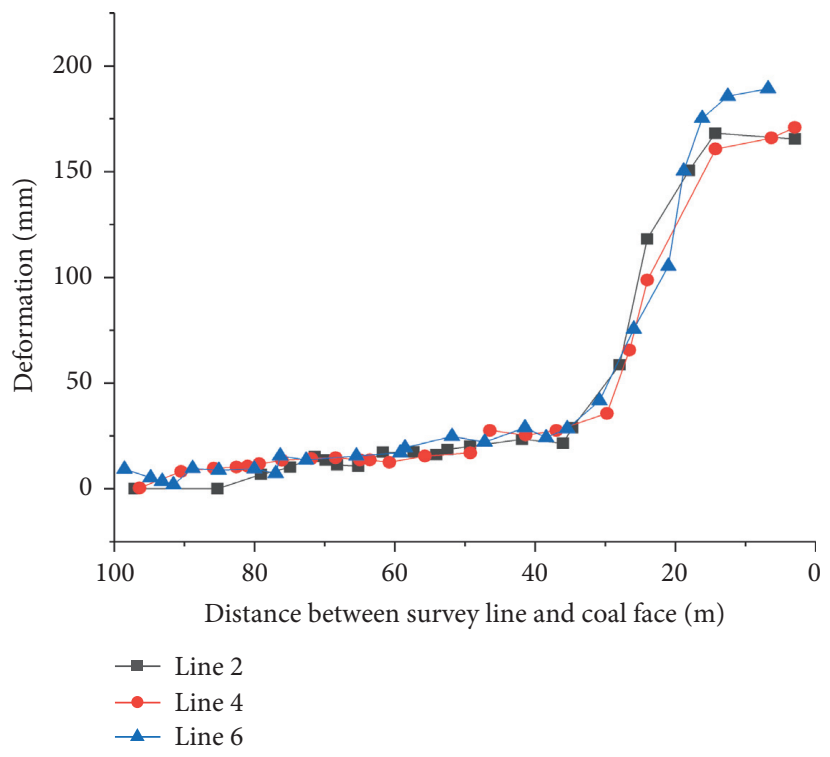

(b)

Figure 24: Displacement of two sides and roof of advance roadway. (a) Deformation of two sides of roadway. (b) Roof subsidence.

coal wall, and three stations are set with a spacing of $10 \mathrm{~m}$, and each station is arranged with two measuring lines to measure the displacement of the between two sides and the roof and floor under the influence of mining disturbance. The displacement change curve is shown in Figure 24.

As shown in Figure 24, the displacement of both sides and roof of tailentry is small, the displacement of two sides is controlled within $160 \mathrm{~mm}$, and the displacement of roof is controlled within $200 \mathrm{~mm}$. It can be seen from each curve that the mining of working face has little influence on the displacement of two sides and roof subsidence of the roadway that is $30 \mathrm{~m}$ away from the coal wall, basically within $25 \mathrm{~mm}$, and almost no effect on the roadway beyond $70 \mathrm{~m}$; the mining disturbance has a greater impact on the surrounding rock deformation of the roadway within $20 \mathrm{~m}$ from the coal wall. According to the curve 2, 4, and 6, the obvious change distance is $26.7 \mathrm{~m}, 26.3 \mathrm{~m}$, and $25.8 \mathrm{~m}$, respectively, and the sharp change distance is $15.6 \mathrm{~m}, 16.1 \mathrm{~m}$, and $15.8 \mathrm{~m}$, reaching the peak value around $8 \mathrm{~m}$. The actual observation under the shaft shows that the deformation of surrounding rock on the roadway surface is small beyond $25 \mathrm{~m}$ in front of the coal wall. After entering the advanced support section, the deformation of the two sides begins to show gradually, mainly with longitudinal crack expansion and local shallow small flakes. However, the roof is complete and stable. Therefore, the selection of roadway location and coal pillar width has played a good role.

6.3.2. Abutment Pressure Distribution Law of Working Face. Selecting the advanced abutment pressure measuring points of 2\# (hole depth of $5 \mathrm{~m}$ ), $4 \#$ (hole depth of $10 \mathrm{~m}$ ), and $5 \#$ 


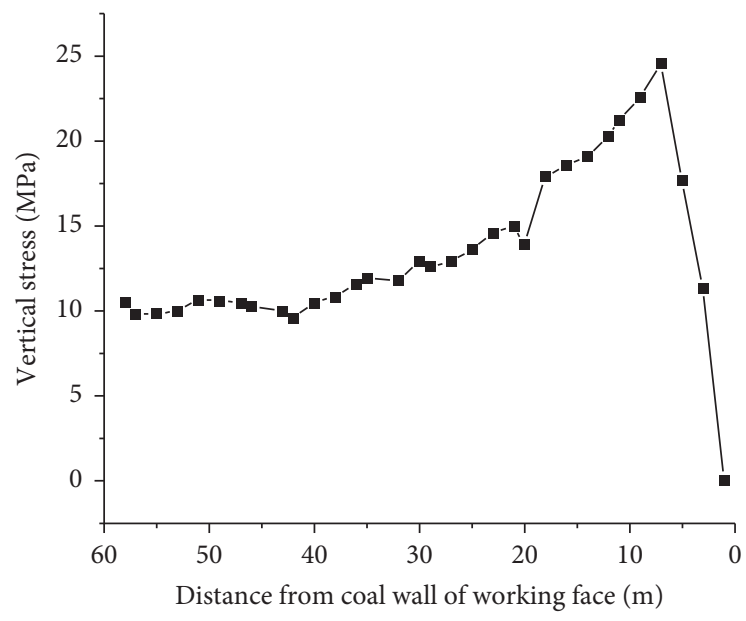

(a)

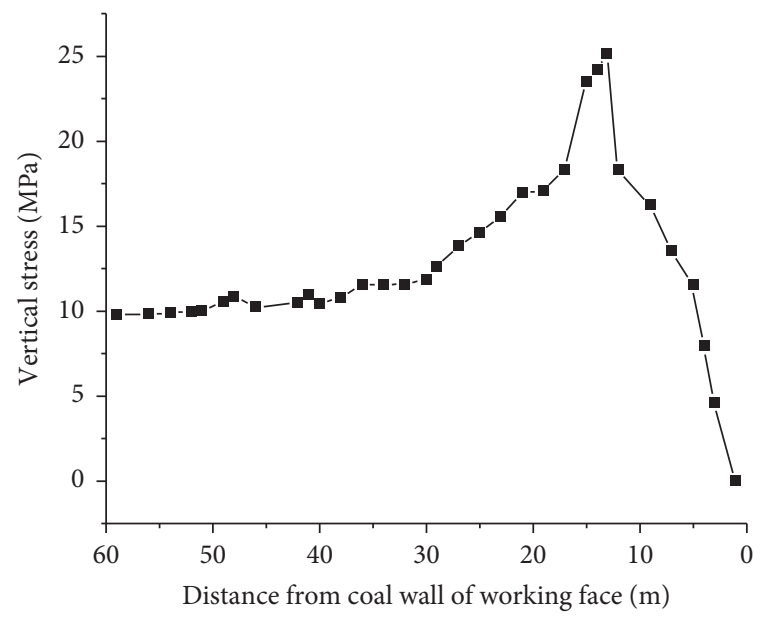

(b)

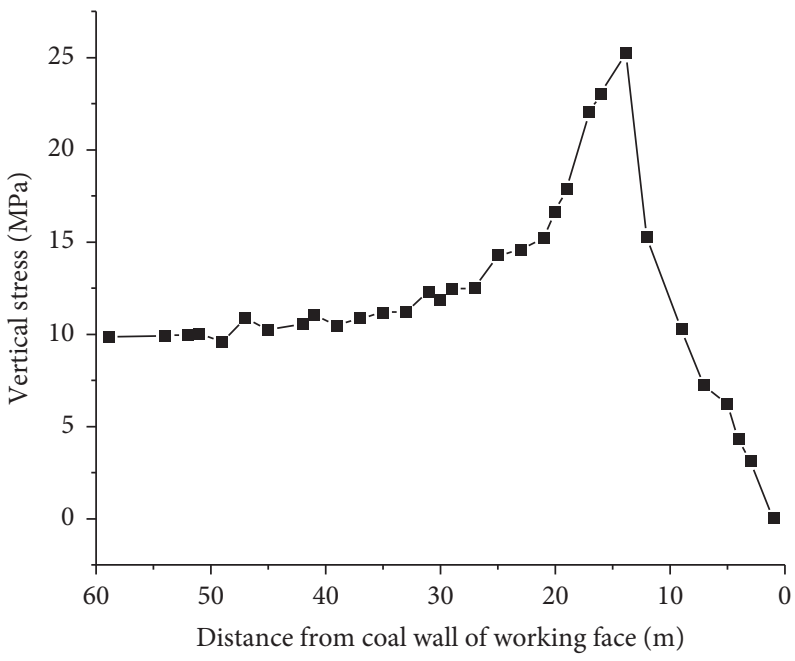

(c)

Figure 25: Variation curve of advance abutment pressure. (a) 2\# (5 m) measuring point. (b) $4 \#(10 \mathrm{~m})$ measuring point. (c) 5\# (12 m) measuring point.

(hole depth of $12 \mathrm{~m}$ ) in the abutment pressure measuring area, extract the data collected by the sensor and the distance to the coal wall, and generate the variation curve of advanced abutment pressure, as shown in Figure 25.

It can be seen from Figure 25 that along the strike of the working face, with the pushing mining of the working face, when the distance between the coal wall of the working face and the measuring point is $35 \mathrm{~m}$ away from the measuring point, the measured value of each measuring point changes slightly; when the distance between the measuring point $2 \#$ and the coal wall is $19 \mathrm{~m}$, the distance between the measuring point 4\# and the coal wall is $16 \mathrm{~m}$; and when the distance between the measuring point 5\# and the coal wall is $20 \mathrm{~m}$, the stress value of the measuring point increases rapidly. When 2\# measuring point is $10 \mathrm{~m}$ away from coal wall, 4\# measuring point is $14 \mathrm{~m}$ away from coal wall, and 5\# measuring point is $13.5 \mathrm{~m}$ away from coal wall, the stress value of measuring point reaches the peak value and begins to decrease gradually. To sum up, the influence range of advance abutment pressure is $35 \mathrm{~m}$, the range of severe influence of advance abutment pressure is $18.3 \mathrm{~m}$, and the average distance of peak value of advance abutment pressure is $12.5 \mathrm{~m}$.

During the mining period, with the continuous change of the distance between each measuring point and the coal wall, the lateral stress curve along the advancing direction of the working face is generated by the values of each measuring point. It can be seen from Figure 26 that the change trend of abutment pressure in the lateral coal pillar of working face is relatively gentle in the early stage, and the stress value of each measuring point changes very little in the area $15 \sim 20 \mathrm{~m}$ away from the coal wall; in the area within $15 \mathrm{~m}$ away from the coal wall, the abutment pressure increases in varying degrees with the advance of the working face, among which the $7 \#$ measuring point $(4 \mathrm{~m})$ rises most obviously.

When the station enters the goaf within $0 \sim 10 \mathrm{~m}$, the abutment pressure rises for a section and then decreases gradually with the advance of working face. The results show 


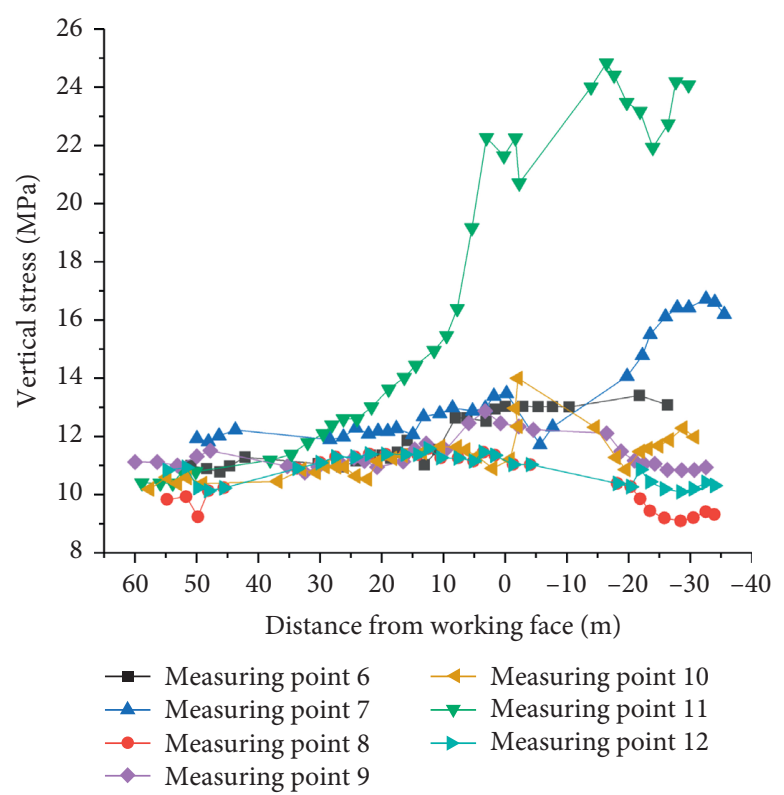

FIGURE 26: Variation curve of side abutment pressure.
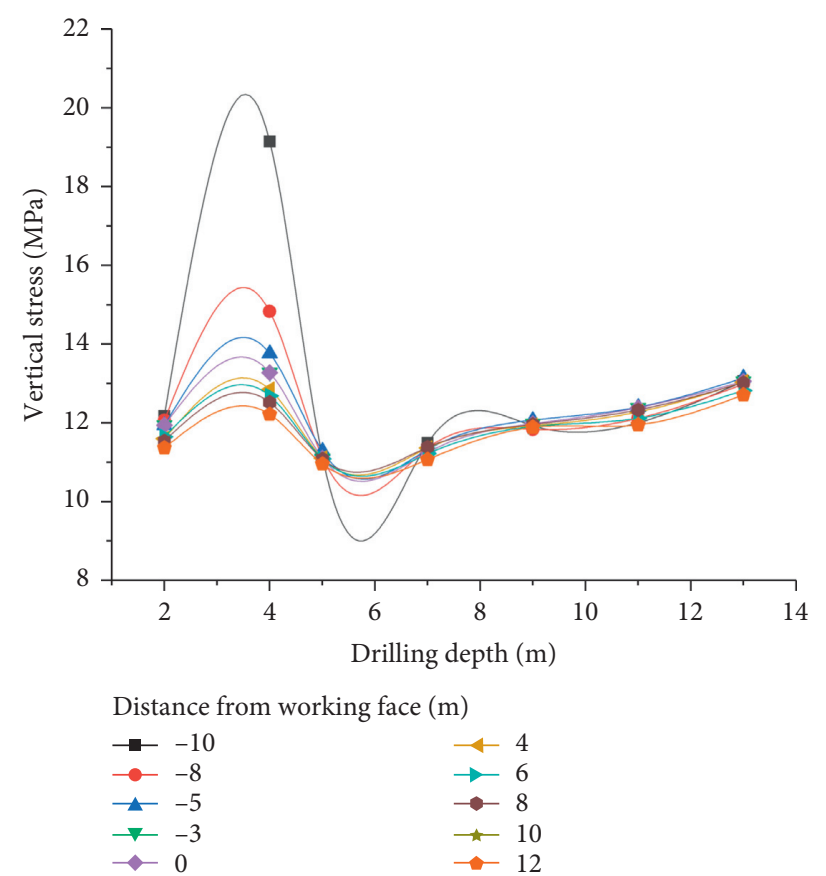

Figure 27: Variation trend of lateral abutment pressure.

that the increase in $7 \#$ measuring point $(4 \mathrm{~m})$ and $6 \#$ measuring point $(2 \mathrm{~m})$ is the most obvious; when the measuring station is more than $20 \mathrm{~m}$ away from the goaf, the abutment pressure of $11 \#$ measuring point $(11 \mathrm{~m}), 7 \#$ measuring point $(4 \mathrm{~m})$, and $6 \#$ measuring point $(2 \mathrm{~m})$ further increases. The stress of $10 \#$ measuring point $(9 \mathrm{~m}), 9 \#$ measuring point $(7 \mathrm{~m})$, and $8 \#$ measuring point $(5 \mathrm{~m})$ gradually decreased, among which the pressure value of $12 \#$ measuring point $(13 \mathrm{~m})$ with the deepest hole depth remained around $11 \mathrm{MPa}$, indicating that the influence of working face mining on the coal body more than $13 \mathrm{~m}$ laterally is not obvious.

Draw a curve for the measured values of each measuring point at the same distance from the coal wall, as shown in Figure 27. It can be seen from Figure 27 that the peak value of the lateral abutment pressure of the working face is the largest at about $3 \mathrm{~m} \sim 4 \mathrm{~m}$ away from the coal side of the roadway, with an increase in $5 \mathrm{MPa}$, which is obviously higher than that of other depth measuring points, and the pressure increases and changes more obviously with the 
point entering the goaf. Combined with the production conditions of 1310 working face, the three-dimensional spatial layout, and quantity of measuring points, the variation distribution law of monitoring data is comprehensively analyzed, and the variation range of lateral abutment pressure is preliminarily determined to be $3 \mathrm{~m} \sim 4 \mathrm{~m}$ away from the roadway coal wall. In conclusion, it is reasonable to reserve a section coal pillar with a width of $5 \mathrm{~m}$.

\section{Discussion}

Domestic and foreign scholars have done a lot of research on roadway reasonable location layout and reasonable dimension determination of section pillar $[13,15,16,22]$ and have obtained relevant conclusions under specific geological conditions or mining technology conditions. However, with the further research, the research on reasonable location of roadway layout and the dimension of section pillar in Jining Jinqiao Coal Mine is less.

In this study, the reasonable layout range of the tailentry under the strip coal pillar is determined through the relevant theoretical analysis. Through the similar material simulation experiment and numerical simulation experiment, the vertical stress distribution law, surrounding rock deformation, and plastic failure law in the coal pillar with different width are studied. Finally, the optimal section coal pillar width and the reasonable position of the tailentry are determined. In this study, the numerical simulation experiment is carried out based on the geological conditions of 1310 working face in Jining Jinqiao Coal Mine, and the research results are applicable to the mining of this mine or the working face with similar geological conditions. In the future, it is necessary to carry out a more detailed study on the reasonable position of the mining roadway under the strip coal pillar under the influence of various factors, such as different buried depth, different coal and rock strength, and different dip angles, which make the research results more universal.

\section{Conclusion}

(1) According to the plane strain problem of elastic mechanics, the study researches the stress distribution at the bottom of the remaining strip coal pillar. Through the study, it is found that the stress concentration in the central area of the bottom of the coal pillar is serious, the stress concentration coefficient is large, and the stress reduction area is within $10 \mathrm{~m}$ of the bottom edge of the coal pillars on both sides. Through the elastic-plastic theory and slip line field theory, the mechanical calculation model of the goaf on the right side of the strip coal pillar is established. The damage range $h_{1}$ is $5.0 \mathrm{~m}$, and the failure range $h_{2}$ is $11.9 \mathrm{~m}$.

(2) Through the analysis of similar material simulation experiment results, it can be seen that the internal stress in a certain area near the edge of 1308 goaf at the bottom of strip coal pillar is low; when the width of coal pillar is $5 \mathrm{~m}$, the floor pressure of goaf on both sides increases, the bearing pressure of coal pillar decreases, and the coal pillar can maintain good supporting function; when the width of coal pillar is $5 \mathrm{~m}$, the peak value of internal stress in coal pillar is the minimum value, and with the increase in coal pillar width, the peak stress increases.

(3) Through the numerical model analysis of the working face under the strip coal pillar, it can be seen that when the width of the coal pillar is $5 \mathrm{~m}$, the plastic failure occurs in the coal pillar, but the bearing capacity is still good; the vertical stress in the coal pillar is greater than the initial stress; however, the stress concentration is not large; the deformation of the surrounding rock of the tailentry is small, and the roadway maintenance is easy.

(4) Finally, it is determined that the tailentry of 1310 working face is located at the bottom of the coal seam near the goaf side of 1308 working face, and the industrial experiment is carried out. Through the field monitoring data, it is reasonable to determine the position of the tailentry and the width of the $5 \mathrm{~m}$ section coal pillar in this study for the working face under the 1310 coal pillar in Jinqiao Coal Mine.

\section{Data Availability}

All data are included within the article or available from the corresponding author upon request.

\section{Conflicts of Interest}

The authors declare that they have no conflicts of interest.

\section{Acknowledgments}

This work was supported by the National Key Research and Development Program (2018YFC0604700).

\section{References}

[1] J. T. Chen, Study on Simulation Test of Strip Pillar Stability under Deep Mining in Tangkou Coal mine, Shandong University of Science and Technology, Qingdao, China, 2011.

[2] W. Liu, Z. Guo, S. Niu, J. Hou, F. Zhang, and C. He, "Mechanical properties and damage evolution behavior of coal-fired slag concrete under uniaxial compression based on acoustic emission monitoring technology," Journal of Materials Research and Technology, vol. 9, no. 5, pp. 95379549, 2020.

[3] S. J. Chen, Basci Experimental Study on Long-Term Stability of Deep Strip Coal Pillar, Shandong University of Science and Technology, Qingdao, China, 2009.

[4] S. J. Chen, Z. W. Du, Z. Zhang, H. W. Zhang, Z. G. Xia, and F. Feng, "Effects of chloride on the early mechanical properties and microstructure of gangue-cemented paste backfill," Construction and Building Materials, vol. 235, Article ID 117504, 2020.

[5] W. Mu, L. Li, T. Yang, G. Yu, and Y. Han, "Numerical investigation on a grouting mechanism with slurry-rock coupling and shear displacement in a single rough fracture," 
Bulletin of Engineering Geology and the Environment, vol. 78, no. 8, pp. 6159-6177, 2019.

[6] W. Mu, L. Li, T. Yang, L. Yao, and S. Wang, "Numerical calculation and multi-factor analysis of slurry diffusion in an inclined geological fracture," Hydrogeology Journal, vol. 28, no. 3, pp. 1107-1124, 2020.

[7] D. Xue, J. Zhou, Y. Liu, and L. Gao, "On the excavationinduced stress drop in damaged coal considering a coupled yield and failure criterion," International Journal of Coal Science \& Technology, vol. 7, no. 1, pp. 58-67, 2020.

[8] Z. H. Zhao, M. Z. Zhang, Q. Ma, and B. S. Chen, "Deviation effect of coaxiality on the rock brazilian split," Advances in Mathematical Physics, vol. 2020, Article ID 5782457, 8 pages, 2020.

[9] B. Xu, "Determination of reasonable width of coal pillar in fully mechanized caving face section of thick no. 1 coal mine," Engineering and Technological Research, vol. 4, no. 17, pp. 6-10, 2019.

[10] M. Geng, Research on 3D Model of Mine System, Liaoning University of Engineering and Technology, Jinzhou, China, 2009.

[11] D. Y. Hao, Y. Z. Wu, H. J. Chen, X. Q. Chu, and Y. Li, "Instability mechanism and prevention technology of roadway in close distance and extra thick coal seam under goaf," Journal Of China Coal Society, vol. 44, no. 9, pp. 2682-2690, 2019.

[12] S. X. Hu, X. L. Xu, S. C. Tian, and B. Zhang, "Optimization of roadway location in lower coal seam from synergy mechanism of contiguous seam mining," Journal of Mining \& Safety Engineering, vol. 33, no. 6, pp. 1008-1013, 2016.

[13] Y. P. Wu, J. Y. Huangfu, S. H. Luo, Y. Q. Wu, B. H. Liu, and W. H. Liu, "Overburden movement and roof failure characteristics in steeply dipping and close distance coal seam mining," Journal of Xi'an University of Science and Technology, vol. 44, no. 1, pp. 1-10, 2020.

[14] X. Y. Zhang, J. G. Liu, and M. Tu, "Overlying rock movement and pressure control in fully mechanized coal caving with weakly bonded roof," Journal of Mining \& Safety Engineering, vol. 36, no. 5, pp. 873-878, 2019.

[15] Q. Y. Xu, Q. G. Huang, and G. C. Zhang, "Fracture and instability mechanism and control technology of a narrow coal pillar in an entry in fully mechanized caving mining under intense effect mining," Journal of Mining \& Safety Engineering, vol. 36, no. 5, pp. 941-948, 2019.

[16] G. Feng and P. Wang, "Simulation of recovery of upper remnant coal pillar while mining the ultra-close lower panel using longwall top coal caving," International Journal of Mining Science and Technology, vol. 30, no. 1, pp. 55-61, 2020.

[17] J. Kang, W. Shen, J. Bai et al., "Influence of abnormal stress under a residual bearing coal pillar on the stability of a mine entry," International Journal of Mining Science and Technology, vol. 27, no. 6, pp. 945-954, 2017.

[18] H. W. Zhang, Z. J. Wan, and Z. Y. Ma, "Stability control of narrow coal pillars in gob-side entry driving for the LTCC with unstable overlying strata: a case study," Arabian Journal of Geosciences, vol. 11, no. 22, p. 665, 2018.

[19] A. M. Suchowerska, R. S. Merifield, and J. P. Carter, "Vertical stress changes in multi-seam mining under supercritical longwall panels," International Journal of Rock Mechanics and Mining Sciences, vol. 61, pp. 306-320, 2013.

[20] R. S. Zhu, "Rational location and support technology of mining gateway in seam with ultra closed distance to above seam," Coal Science and Technology, vol. 40, no. 4, pp. 10-13, 2012.
[21] Z. Y. Wei, "Gateway layout of ultra thick contigous seam group in tashan coal mine," Coal Science and Technology, vol. 41, no. 1, pp. 46-48, 2013.

[22] H. L. Zhang and L. G. Wang, "Computation of mining induced floor additional stress and its application," Journal of Mining \& Safety Engineering, vol. 28, no. 2, pp. 288-292, 2011.

[23] L. Xu, J. B. Bai, X. Y. Wang, Y. Xu, Y. Yu, and K. X. Zhang, "Roadway surrounding rock control technology under the influence of coal pillar abutment pressure," Safety in Coal Mines, vol. 42, no. 4, pp. 51-53, 2011.

[24] B. S. Zhang, S. S. Yang, L. X. Kang, and Y. D. Zhai, "Discussion on method for determining reasonable position of roadway for ultra-close multi-seam," Chinese Journal of Rock Mechanics and Engineering, vol. 1, pp. 97-101, 2008.

[25] D. Z. Kong, Z. H. Wang, and Z. C. Ren, "Determining the optimum position of roadways of full-mechanized caving face in the close distance seams," Journal of Mining \& Safety Engineering, vol. 31, no. 2, pp. 270-276, 2014.

[26] C. J. Hou and N. J. Ma, "Discussion on stress and limit equilibrium zone of two sides of coal seam roadway," Journal of China Coal Society, vol. 4, pp. 21-29, 1989.

[27] Q. Wang, H. K. Gao, B. Jiang et al., "Research on reasonable coal pillar width of roadway driven along goaf in deep mine," Arabian Journal of Geosciences, vol. 10, no. 21, p. 466, 2017.

[28] J. Li, B. Q. Xu, W. S. Wang, and F. Wang, "Distribution Law of principal stress difference of deep surrounding rock of gobside entry and optimum design of coal pillar width," Tehnicki Vjesnik, vol. 26, no. 6, pp. 1746-1752, 2019.

[29] X. S. Liu, J. G. Ning, Y. L. Tan, C. L. Tian, and J. Wang, "Optimization of coal pillar width in shallow seam with soft roof," Electronic Journal of Geotechnical Engineering, vol. 19, no. 2, pp. 10007-10016, 2014.

[30] X. Yang, C. Hu, M. He et al., "Study on presplitting blasting the roof strata of adjacent roadway to control roadway deformation," Shock and Vibration, vol. 2019, Article ID 3174898, 16 pages, 2019.

[31] X. Yang, C. Hu, J. Liang, Y. Zhou, G. Ni, and R. Huang, "A case study on the control of large deformations in a roadway located in the Duerping coal mine in China," Advances in Materials Science and Engineering, vol. 2019, Article ID 9628142, 13 pages, 2019.

[32] Z. Zhao, W. Sun, M. Zhang, X. Gao, and S. Chen, "Fracture mechanical behavior of cracked cantilever roof with large cutting height mining," Shock and Vibration, vol. 2020, Article ID 1641382, 10 pages, 2020.

[33] Q. Xu, Study on Stress Transfer Law and Reasonable Size of Coal Pillar in Multi Seam Mining, Shandong University of Science and Technology, Qingdao, China, 2019.

[34] S. Ning, Study on Deformation Characteristics of Surrounding Rock and Segmented Control Technology of Cross Mining and Crossing Strata Roadway, Shandong University of Science and Technology, Qingdao, China, 2019.

[35] H. J. Xu, Study on Mining Roadway Arrangement and Support Technology in Ultra-close Multiple-Seams Mining, China University of Mining and Technology, Xuzhou, China, 2016.

[36] Z. Q. Song, "Theory of internal and external stress field and its application in mine pressure control," in Proceedings of the North China Conference on Rock Mechanics and Engineering Application, Norman, OK, USA, July 1991.

[37] J. K. Lv, Study on Gob-Side Entry Retaining Technology of Small Coal Pillar in Deep and Thick Seam, Shandong University of Science and Technology, Qingdao, China, 2019. 